\title{
Trajectories of Boredom in Self-Control Demanding Tasks
}

\author{
Maik Bieleke ${ }^{1}$, Leon Barton², and Wanja Wolff ${ }^{3,4}$ \\ ${ }^{1}$ Department of Developmental and Educational Psychology, University of Vienna, Austria \\ 2 Department of Psychology, University of Konstanz, Germany \\ ${ }^{3}$ Department of Sport Science, University of Konstanz, Germany \\ ${ }^{4}$ Department of Educational Psychology, University of Bern, Switzerland
}

This article has been accepted for publication in Cognition and Emotion, published by Taylor \& Francis. Please cite it as follows:

Bieleke, M., Barton, L., \& Wolff, W. (2021). Trajectories of boredom in self-control demanding tasks. Cognition and Emotion. Advance online publication.

\begin{abstract}
Author Note
Correspondence concerning the article should be addressed to Maik Bieleke, University of Vienna, Austria, Phone: +43-1-4277-47404, Email: maik.bieleke@univie.ac.at
\end{abstract}




\begin{abstract}
Self-control does not always work effectively. Whether this reflects the depletion of a global self-control resource is subject to an ongoing debate. We turned to boredom as a potential confounding variable to advance this debate. In a high-powered experiment $(N=719)$, participants worked on a primary (transcription) tasks of varying self-control demands (low, high) and length (2, 4, 8 minutes), followed by a secondary (Stroop) task with low and high selfcontrol demanding trials. In addition to trait boredom, we measured effort, difficulty, tiredness, frustration, and boredom after the primary task and repeatedly during the secondary task. Effort, difficulty, tiredness, and frustration increased with the demand and duration of the primary task; however, without affecting performance in the secondary task. Importantly, participants rated both the primary and the secondary task as boring, and higher boredom at the state and the trait level was associated with lower effort and higher difficulty, tiredness, and frustration. During the secondary task, boredom increased steadily but was generally lower in more self-control demanding trials. Finally, boredom predicted performance in the secondary task. These results show an intricate relationship between self-control and boredom that research on these two constructs should carefully disentangle.
\end{abstract}

Keywords: boredom; ego depletion; self-control; goals; motivation 


\section{Trajectories of Boredom in Self-Control Demanding Tasks}

Goal attainment often hinges on self-control. For instance, self-control is required to resist the temptation to eat unhealthy snacks when the goal is to lose weight or to stop watching TV and go for a run when the goal is to be physically active. However, people sometimes fail to summon the self-control that is necessary to attain a goal (Vohs \& Heatherton, 2000) and might find themselves snacking in front of the TV. A prominent explanation for such apparent self-control failures is provided by the strength model of self-control (Baumeister et al., 1998), which asserts that self-control rests on the availability of a global, limited resource. Any act of self-control is assumed to deplete this resource and because it is not immediately replenished, subsequent goal striving is impaired when it draws on this resource as well (e.g., to control attention and emotions). This state of temporarily exhausted self-control is referred to as ego depletion (e.g., Baumeister et al., 1998). Returning to the initial example, after a cognitively demanding day with repeated self-control exertions, people might just not have the self-control resources that are required to resist temptations like delicious snacks or their favorite TV show.

Experiments testing the assumptions of the strength model of self-control commonly rely on the sequential task paradigm, which consists of a primary and a secondary task. Performance in the primary task (e.g., transcribing a text) requires either little self-control (e.g., no special rules have to be observed; low-demand condition) or much self-control (e.g., frequently occurring letters like " $\mathrm{e}$ " have to be omitted; high-demand condition). This difference in self-control demands is thought to result in ego depletion in the high-demand but not in the low-demand condition. In the following secondary task (e.g., a Stroop task) all participants then 
have to apply self-control. The central prediction of the strength model of self-control is that, due to ego depletion, participants in the high-demand condition perform worse in this secondary task than participants in the low-demand condition. Numerous studies have tested this prediction and found support for the ego depletion effect (meta-analysis by Hagger et al., 2010). However, re-analyses of the available evidence suggest that the ego depletion effect might have been overestimated, for instance, as a result of publication bias (Carter \& McCullough, 2013; Wolff et al., 2018). Moreover, there have been repeated failures to replicate the ego depletion effect (e.g., Hagger et al., 2016). These inconsistencies provide the grounds for an ongoing debate about whether or not the ego depletion effect actually exists.

Several ways of advancing this debate have been suggested. Some researchers pointed to differences in the setup of the sequential task paradigm that might have inadvertently introduced confounds (Lee et al., 2016). For instance, the idea of a depletable resource suggests that the time participants spend working on the primary task is critical for the occurrence of the ego depletion effect in the secondary task (Hagger et al., 2010). Failures to observe the effect might thus be due to primary tasks being too short to induce ego depletion. Discouraging this explanation, however, studies that have systematically varied the length of the primary task still failed to observe ego depletion effects on performance (Wolff et al., 2019). Moreover, there appears to be no robust link between the length of the primary task and the size of the ego depletion effect across independent studies (Giboin \& Wolff, 2019). Another explanation for the inconsistencies in the literature on ego depletion might be the effect of unmeasured confounding variables in studies relying on the sequential task paradigm. One such variable that has attracted attention is the experience of boredom during the self-control demanding tasks 
(e.g., Milyavskaya et al., 2019; Wolff \& Martarelli, 2020).

Boredom is an aversive experience that emerges when people fail to successfully engage in satisfying activities (Eastwood et al., 2012). More specifically, theoretic accounts of the determinants of boredom (e.g., control-value theory, Pekrun, 2006; meaning and attention model; Westgate \& Wilson, 2018; see also Csikszentmihalyi, 2000) postulate that people feel bored in situations that are characterized by (1) low meaning (i.e., an uninteresting and nonrewarding task) and/or by (2) a mismatch between task demands and cognitive resources (i.e., being under- or over-challenged). Each one of these two characteristics is sufficient to induce boredom, making it a regular experience for most people across various situations (Chin et al., 2017). Of particular relevance for the present paper, current conceptual work points toward a strong link between boredom and self-control, which suggests that boredom is likely to play a role in ego depletion studies too (Wolff \& Martarelli, 2020). This argument is based on the observation that tasks that are used in ego depletion research to impose varying levels of selfcontrol demands are sometimes also used in boredom research to induce boredom. Indeed, within the propositions of the MAC model, many of the frequently used self-control tasks also have properties that are likely to render them very boring. First, tasks like transcribing a text or categorizing stimuli that are presented on a computer screen are likely to be perceived as rather meaningless because they are not intrinsically interesting and participants only complete them to receive a (mostly performance-independent) reimbursement afterward (Wolff et al., 2019; Wolff \& Martarelli, 2020). Second, the attempt to vary self-control demands could inadvertently lead to under-challenge in low-demand conditions and over-challenge in high-demand conditions. Importantly, due to learning, the self-control demands of any given task are likely to 
change as a function of task duration. Thus, a task that was initially boring because it was overchallenging might be not boring for a while, before becoming boring again due to underchallenge. Taken together, this suggests that participants might feel bored when working on self-control demanding tasks.

Further, it is plausible that boredom does not merely occur in self-control demanding tasks but that it is also systematically associated with self-control and performance in these tasks. For instance, the shifting priorities model of self-control (Inzlicht \& Schmeichel, 2012) suggests that engaging in a primary self-control demanding task initiates motivational and attentional processes that affect performance in a secondary task (e.g., reduced motivation to exert control, increased attention to rewards). Motivational processes are a key constituent of the experience of boredom (e.g., Pekrun et al., 2010). According to functional accounts of boredom (e.g., Bench \& Lench, 2019), boredom signals that an ongoing activity might not be worth being pursued and that alternative, potentially more rewarding activities should be pursued instead. Accordingly, boredom motivates people to avoid or escape the aversive experience of boredom. This implies a devaluation of the ongoing activity, which should amplify the costs associated with its maintenance and thereby reduce the effort people invest in it. In this sense, boredom constitutes a relevant self-control demand that people have to deal with on top of the demands inflicted by performing the task itself (e.g., Bieleke et al., 2021; Wolff et al., 2020). Moreover, by making alternative, potentially more rewarding activities salient, boredom also creates an urge to change one's behavior (Geana et al., 2016; Gomez-Ramirez \& Costa, 2017). Accordingly, boredom is not an affectively neutral state of amotivation or disinterest; rather, it creates a motivation to explore the environment beyond the task at hand (Bieleke \& 
Wolff, in press). This is supported by the finding that boredom increases reward sensitivity (Milyavskaya et al., 2019), which might prompt people to rush through self-control tasks rather carelessly in order to get ready for new activities .

Besides its motivational properties, boredom also has downstream consequences for attention (Eastwood et al., 2012). Specifically, people struggle with staying mentally engaged in a boring task because their attention turns to alternative tasks (Westgate \& Wilson, 2018). This dilutes the attentional resources that are deployed in the ongoing activity (Hunter \& Eastwood, 2018). As attentional resources are critically important for effective self-control (Schmeichel \& Baumeister, 2010), boredom is likely to adversely affect self-control performance. Taken together, the experience of boredom is accompanied by motivational and attentional processes that are relevant in self-control demanding tasks (Inzlicht \& Schmeichel, 2012). At the same time, boredom can be distinguished from other potentially relevant motivational processes especially due to its aversiveness (e.g., lack of motivation, disinterest in the task). As such, boredom has been identified as a promising concept for advancing the understanding of inconsistencies in the ego depletion literature.

\section{Present Research}

Mechanistic theories of boredom suggest that people are likely to feel bored in selfcontrol demanding tasks. Moreover, this experience of boredom could be systematically associated with subjective perceptions of self-control (effort, difficulty, frustration, and tiredness) and performance. As such, studying the trajectories of boredom in the sequential task paradigms used to examine the ego depletion effect is a timely and promising step to understanding inconsistent findings in the ego depletion literature. We conducted a high- 
powered experiment in which we measured experiences of boredom at critical points of the sequential task paradigm: once immediately after the primary task and repeatedly during the secondary task. Also, we measured stable individual differences in the propensity to experience boredom (i.e., trait boredom). We then examined associations of boredom at the state and trait level with effort, difficulty, frustration, and tiredness during the secondary task. Moreover, we investigated the predictive role of (state and trait) boredom for secondary task performance.

Based on the literature reviewed above, boredom should emerge in both the primary and the secondary tasks, and higher levels of boredom should be associated with reduced effort and with increased difficulty, frustration, and tiredness. Specifically, boredom should instigate a drive to engage in different activities, which requires self-control to be regulated and makes it less worthwhile to invest further effort. An analogous pattern of associations with effort, difficulty, frustration, tiredness can be expected for trait boredom. We also examined the idea that boredom might vary as a function of characteristics of the primary and the secondary task, in particular the self-control demands imposed by these tasks and their length. Finally, differences in boredom on the group or individual level after the primary task should be associated with performance in the secondary task.

\section{Methods}

We employed a sequential task paradigm consisting of a primary transcription task and a secondary Stroop task, varying the time participants had to work on the transcription task (i.e., 2, 4, or 8 minutes; see Wolff et al., 2019, for a similar procedure). The Stroop task provides two quantitative and traceable measures of performance (i.e., response times and error rates). Moreover, we could vary the self-control demands of the Stroop task by using modified task 
instructions, allowing us to assess the effect of added self-control demands on self-controlled performance and the sensation of boredom.

\section{Design and Participants}

We established six conditions by varying the Demand (low, high) and the Time $(2,4,8$ minutes) of the transcription task between participants. In the Stroop task, we implemented three within-participant factors: We established trials in which the semantic meaning and the font color of the word were congruent versus incongruent (Congruency), varied whether participants received the standard instruction to classify the color of the font versus the modified instruction to classify the meaning of the word (Instruction), and distributed these different trials randomly across five subsequent blocks (Block). Detecting small-to-medium effects $(f=.175)$ with $95 \%$ power requiring at least 500 participants. We recruited 719 participants via Amazon MTurk who completed the experiment (323 females, 47.4\%, age: $M=$ 37.4 years, $S D=11.5$ ). Participants were randomly assigned to conditions ( $\min =115, \max =$ 121). There were no differences between conditions with regard to demographic characteristics (age, gender, education, employment, ethnicity) or trait boredom, $p \geq .07$. For the analysis of the Stroop task, data from 674 participants were available after excluding outliers. Further details about participant recruitment, demographic characteristics, and data exclusions are provided in the supplementary materials (e.g., Table S1). All participants gave informed consent before the experiment.

\section{Materials and Procedure}

All materials used in the present research can be accessed from the OSF https://osf.io/m4fgp/). Participants first worked on the transcription task for 2,4 , or 8 minutes 
and then on the Stroop task for 10 minutes. Once after completing the transcription task and every 2 minutes during the Stroop task they reported their effort, difficulty, frustration, and tiredness as well as their experienced boredom. The experiment concluded with a final questionnaire measuring trait boredom and demographics.

\section{Primary Task: Transcription (Time and Demand)}

Participants transcribed a neutral text for 2, 4, or 8 minutes. In the high-demand condition, they were instructed to leave out the letter "e/E" and space characters, which requires self-control to override dominant writing habits (Wolff et al., 2019). In the low-demand condition, participants had not to omit any letters.

\section{Secondary Task: Stroop (Congruency, Instruction, and Block)}

The Stroop task comprised a randomized series of color words that participants classified by pressing buttons on the keyboard. The semantic meaning of the words either matched their font color (congruent stimuli; e.g., the word "red" displayed in red) or not (incongruent stimuli; e.g., the word "red" displayed in green) with equal probability. In $80 \%$ of the trials, participants had to classify the font color (standard instructions), which requires selfcontrol to suppress the dominant tendency to process the semantic meaning of words. In the remaining $20 \%$ of the trials, participants had to classify the semantic meaning of the word (modified instructions), which requires additional self-control to switch to an uncommon instruction. The Stroop task was divided into a sequence of five blocks, each lasting two minutes. In each block congruent/incongruent trials and standard/modified instructions were presented in random order. Participants reported effort, difficulty, frustration, tiredness, and boredom separately for trials under standard and modified instructions. Performance was 
measured in terms of response times and errors.

\section{Task Perceptions}

We used four single items to measure effort ("I put a lot of effort in the [task]"), difficulty ("I think the [task] was very difficult"), tiredness ("I feel very tired after the [task]"), frustration ("I felt very frustrated while doing the [task]"), as these variables are commonly assessed as manipulation checks in ego-depletion research (Hagger et al., 2016). Additionally, we measured state boredom ("I think the [task] was very boring"). Answers were provided on Likert scales (1 = totally disagree, 7 = totally agree).

\section{Final Questionnaire}

We measured trait boredom with the short version of the boredom proneness scale (Struk et al., 2017), which consists of 8 items to be answered on a 7-point Likert scale (1 = strongly disagree, 7 = strongly agree). Example items include "It takes more stimulation to get me going than most people," "I often find myself at 'loose ends,' not knowing what to do," and "I find it hard to entertain myself." The scale showed very good internal consistency, $\alpha=.90$. We also assessed demographic information.

\section{Analytic Approach}

The analysis scripts and all data can be accessed from the OSF (https://osf.io/m4fgp/). In the transcription and the Stroop task, we subjected task perceptions (effort, difficulty, frustration, tiredness, boredom) and performance measures (response times, error rates) to ANOVAs to analyze the effects of our experimental manipulations (between-factors: Demand, Time; within-factors in the Stroop task: Instruction, Block, and Stimulus). We further investigated whether performance in the Stroop task was predicted by boredom after the 
transcription task and/or trait boredom using two (generalized) mixed-effects regression models for response times and errors. Also, we estimated a set of latent parameters that characterize the information processing style that led to the observed performance (Lin et al., 2020) using drift-diffusion models (Wagenmakers et al., 2007). These latent parameters include the speed of processing ("drift rate parameter"), the degree to which accuracy is sacrificed for speed ("boundary parameter"), and the duration of preparing and implementing the decision ("nondecisional parameter"). As for response times and errors, we ran a mixed-effects regression for each parameter with boredom after the transcription task and trait boredom as predictors. See supplementary materials for details.

\section{Results}

\section{Perception of the Transcription Task}

Descriptive statistics and intercorrelations of effort, difficulty, frustration, tiredness, and boredom in the transcription task are provided in the supplementary materials (Table S2 (upper part) and Table S3). ${ }^{1}$ Most importantly, participants who perceived the transcription task as more boring (state) or were generally more inclined to experience boredom (trait) invested less effort in the task and perceived it as more difficult, frustrating, and tiresome. These associations were small to medium, indicating that the experience of boredom and the experience of applying self-control are related but distinguishable.

We subjected ratings of effort, difficulty, frustration, tiredness, and state boredom to

\footnotetext{
${ }^{1}$ Note that theoretical accounts of boredom propose a quadratic relationship between difficulty and boredom, for which we found some evidence in our data (see supplementary materials for details).
} 
ANOVAs with Demand (low, high) and Time (2, 4, 8 minutes) as between-participant factors (Table S4). Participants in the high-demand condition perceived the task as more difficult, frustrating, and tiresome than participants in the low-demand condition, $F(1,713) \geq 16.03, p$ $<.001, \eta_{\mathrm{G}}^{2} \geq .022$. The difference was similar for effort but not significant, $F(1,713)=3.09, p$ $=.079, \eta_{\mathrm{G}}^{2}=.004$. Further, longer transcription tasks evoked more effort and were perceived as more difficult and tiresome, $F(2,713) \geq 3.91, p \leq .020, \eta_{\mathrm{G}}^{2} \geq .011$. No interactions emerged between Demand and Time, $p \geq .266$. Finally, state boredom was not influenced by Demand, Time, or their interaction, suggesting that more demanding or longer versions of the transcription task did not induce different levels of boredom.

\section{Perceptions in the Stroop Task}

Descriptive statistics and intercorrelations of effort, difficulty, frustration, tiredness, and boredom in the Stroop task are provided in the supplementary materials (Table S2 (lower part) and Tables S5 and S6). Analogous to the transcription task, participants who perceived the Stroop task as more boring (state) or were generally more inclined to experience boredom (trait) invested less effort in the task and perceived it as more difficult, frustrating, and tiresome.

We subjected ratings of effort, difficulty, frustration, tiredness, and boredom to ANOVAs with Demand (low, high) and Time (2, 4, 8 minutes) as between-participant factors and Block (1, $2,3,4,5)$ and Instruction (standard, reversed) as within-participant factors. Perceptions during the Stroop task were almost exclusively influenced by the effects of Instruction, Block, and their interaction (Table S7, Figure 1). The main effects of Block indicated that participants reduced 
their effort and experienced increasing frustration, tiredness, and boredom over time, $F(4$,

$2644) \geq 16.38, p<.001, \eta_{\mathrm{G}}^{2} \geq .006$. The main effects of Instruction suggest that participants experienced modified Stroop trials as more difficult, frustrating, and tiresome but also as less boring than standard Stroop trials, $F(1,661) \geq 5.99, p \leq .015, \eta_{\mathrm{G}}^{2} \geq .0002$. Interactions of Block and Instruction revealed that these differences decreased over time with regard to effort, difficulty, frustration, and tiredness, $F(4,2644) \geq 2.70, p \leq .035, \eta_{\mathrm{G}}^{2} \geq .0001$, but not with regard to boredom, $F(4,2644)=1.69, p=.157, \eta_{\mathrm{G}}^{2}<.001$.

\section{Performance in the Stroop Task}

Descriptive statistics of Stroop task performance are provided in Tables S8 and S9. We subjected response times and error rates to ANOVAs with Demand (low, high) and Time (2, 4, 8 minutes) as between-participant factors and $\operatorname{Block}(1,2,3,4,5)$, Instruction (standard, reversed), and Stimulus (congruent, incongruent) as within-participant factors. Stroop performance was primarily influenced by Instruction, Stimulus, Block, and interactions between them (see Table S10, Figure 2). Importantly, the demand of the transcription task was not involved in any significant effect.

Regarding response times, we found main effects of Block, Instruction, and Stimulus, as well as their two-way interactions, $F(1 / 4,650 / 2600) \geq 6.74, p<.001, \eta_{\mathrm{G}}^{2} \geq .0004$. These effects suggest that participants became faster over time, and responded generally faster under standard versus modified Stroop instructions and in congruent versus incongruent trials. The difference between Stroop instructions was less pronounced for congruent compared to incongruent stimuli and it decreased over time, as did the difference between congruent and 
incongruent stimuli. Regarding error rates, we found main effects of Block, Instruction, and Stimulus, as well as their two- and three-way interactions, $F(1 / 4,650 / 2600) \geq 23.69, p<.001$, $\eta_{\mathrm{G}}^{2} \geq .003$. These effects suggest that faster responses were generally accompanied by higher error rates (i.e., a speed-accuracy tradeoff) with one exception: error rates in incongruent trials under modified Stroop instructions improved over time.

\section{Boredom and Stroop Performance}

More errors in the Stroop task were associated with higher trait boredom, $\beta=0.070, \mathrm{SE}$ $=0.035, p=.048$, but not with state boredom after the transcription task, $\beta=0.029, \mathrm{SE}=0.023$, $p=.211$. Conversely, response times were associated with state boredom after the transcription task, $\beta=-0.010, \mathrm{SE}=0.005, p=.045$, but not with trait boredom, $\beta=-0.012, \mathrm{SE}=0.007, p$ $=.103$. The diffusion model analysis showed that higher state boredom after the transcription task was associated with a smaller threshold parameter in the Stroop task, $\beta=-0.014$, SE $=$ $0.005, p=.007$, indicating that participants prioritized speed over accuracy. The same finding emerged for trait boredom, $\beta=-0.017, \mathrm{SE}=0.008, p=.038$. Other effects were not significant, $p$ $>$.10. For details, see Table S11. ${ }^{2}$

\section{Discussion}

We examined the trajectories of boredom in self-control demanding tasks and investigated whether boredom might explain inconsistencies in ego depletion research. To this end, we conducted a high-powered experiment based on the sequential task paradigm, in

\footnotetext{
${ }^{2}$ We performed analogous analyses with state boredom during the Stroop task and trait boredom as predictor of performance, which yielded comparable results (see Table S12).
} 
which we measured state boredom along with effort, difficulty, frustration, and tiredness once after the primary (transcription) self-control task and then repeatedly during the secondary (Stroop) self-control task. We also assessed individual differences in general boredom proneness (trait boredom). To establish varying degrees of perceived depletion (Wolff et al., 2019), we varied the self-control demands (low, high) and the time $(2,4,8$ minutes) of the primary task.

Our results replicated earlier studies showing that more self-control demanding and longer versions of the primary task induce higher levels of effort, difficulty, frustration, and tiredness (Wolff et al., 2019). This affected neither the perceived depletion nor the performance in the secondary task, except higher error rates among participants who had worked longer on the transcription task at the beginning of the Stroop task and for incongruent stimuli. Importantly, these effects of time were independent of the self-control demands of the transcription task, which turned out to be inconsequential for the Stroop task perception and performance. Thus, we did not establish an ego depletion effect in our study. Rather, perceived depletion and performance and the secondary task varied almost exclusively as a function of the characteristics of the Stroop task itself. In line with current theorizing on boredom and ego depletion (Westgate \& Wilson, 2018; Wolff et al., 2020), however, working on the primary and the secondary task induced substantial levels of boredom.

\section{Boredom and Performance in the Secondary Task}

\section{The Role of Concurrent Boredom}

Boredom increased steadily during the Stroop task along with decreasing levels of effort and increasing levels of difficulty, frustration, and tiredness. The correlations between boredom and these variables were small-to-medium, suggesting that these constructs are tightly linked 
but still distinct experiences during self-control demanding tasks. On a behavioral level, higher boredom was generally accompanied by a decrease in response times and an increase in error rates. Such a pattern of performance indicates that participants became less and less willing to work diligently on the task, sacrificing accuracy for speed. This is compatible with the assertion that boredom creates an urge to switch to alternative activities, while the perceived costs of self-control are assumed to create an urge to invest less effort in the task (Wolff \& Martarelli, 2020): Participants who are bored and feel depleted by a task can be assumed to try to get over it as quickly as possible, to get ready for new and potentially more rewarding activities.

Teasing apart the genuine roles of boredom and perceived depletion for performance requires situations that participants perceive as depleting but not as boring (or the other way around). In our experiment, this constellation emerged in the infrequent trials with modified Stroop instructions. These trials were much more demanding than the majority of standard trials when the stimulus was incongruent, which becomes evident from stronger perceptions of depletion and slow and error-prone responses. Intriguingly, however, participants reported being less bored in these trials. It is conceivable that participants found trials with incongruent stimuli and modified instructions more engaging because they occurred rarely and were challenging. Interestingly, and contrary to the general pattern of performance, we observed unambiguously improving performance (i.e., shortening response times and decreasing error rates) in incongruent trials under modified instructions. This points to boredom as the more significant driving force behind behavior in self-control demanding tasks, with low boredom prompting people to improve their performance and high boredom encouraging them to sacrifice accuracy for speed. 


\section{The Predictive Role of Boredom}

We assessed state boredom immediately after the primary task as well as trait boredom, which allowed us to examine the predictive role of boredom for performance in the sequential task paradigm. On the group level, boredom did not vary as a function of self-control demands or the length of the primary task. Our data, therefore, provides limited information about possible effects of boredom on performance on the group level. At least we can conclude that the lack of differences between conditions regarding boredom after the primary task and performance in the secondary task does not conflict with the idea that boredom affects performance. This is in contrast with the observation that group differences in effort, difficulty, frustration, and tiredness after the primary task were not accompanied by differences in Stroop performance, which clearly discourages explanations based on the depletion of self-control resources.

Yet, more direct evidence for the predictive role of boredom comes from our analyses on the individual level. We found that participants' state boredom after the transcription task and their trait boredom predicted faster responses and more errors in the Stroop task, respectively. Following up on the cognitive processes underlying these behavioral findings revealed that the more bored participants were after the transcription task, the more they prioritized speed over accuracy in the Stroop task. The same result emerged for trait boredom. It is noteworthy that state boredom after the transcription task and trait boredom were not correlated and that their effects on performance emerged when controlling for each other. Accordingly, boredom affects self-control performance independently as a state and as a trait.

\section{New Impulses for Research on Ego Depletion}


We found that versions of the primary transcription task that differed in terms of selfcontrol demands and length did not induce different levels of boredom, while they did induce different levels of effort, difficulty, frustration, and tiredness. This points to a desirable specificity of the transcription task in creating the conditions that are necessary for investigating ego depletion effects without confounding them with boredom. However, it is difficult to generalize this observation across a variety of tasks that are used as primary tasks. For instance, we found pronounced differences in boredom in the Stroop task depending on its length and, importantly, also concerning its self-control demands. It is thus conceivable that using the Stroop task as a primary task might induce not only self-control specific levels of effort, difficulty, frustration, tiredness but also differential levels of boredom. This suggests that tasks typically used as primary tasks in ego depletion research should be systematically compared concerning their effects on boredom.

At first glance, it may not seem intuitive to assume that some tasks induce different levels of boredom while others do not. However, according to functional models of boredom (Westgate \& Wilson, 2018), boredom requires the situation to be either meaningless or to be characterized by a mismatch between demands and abilities. Concerning meaning, it seems unlikely that variations of the same task in terms of self-control demands or length are perceived as differentially meaningful (as argued, for instance, by Wolff \& Martarelli, 2020). However, it is plausible that tasks differ in their overall difficulty (e.g., transcribing a text might be perceived as generally easier than performing a Stroop task) and that the manipulation of self-control demands with each task additionally taps into the difficulty of the primary task. Both the overall level of difficulty and the difference in difficulty between low and high self- 
control demanding conditions matter for the experience of boredom. On the one hand, people can enjoy easy tasks and find interest in difficult tasks without experiencing any boredom (the "goldilocks" zone of difficulty; Danckert \& Eastwood, 2020; Westgate \& Wilson, 2018). Only when easy tasks become too easy (i.e., under-challenging) or when difficult tasks become too difficult (i.e., over-challenging) boredom might arise from a mismatch between demands and abilities, which can lead to different levels of boredom. For instance, participants could enjoy working on the easy task in the low-demand condition, while those in the high-demand condition might feel over-challenged by the difficult task. Then, more boredom is expected in the high-demand compared to the low-demand condition. To complicate matters further, the difficulty could decrease over time such that an initially easy and enjoyable task becomes dull and boring, whereas an initially over-challenging and boring task could become manageable and interesting. If that was the case, boredom should vary as a function of the general difficulty, the specific self-control demands, and the length of the primary task.

The argument that different primary tasks might induce different levels of boredom is particularly relevant because performance in the Stroop task in our study was susceptible to lingering state boredom induced by the primary task on the individual level, as well as to individual differences in trait boredom. As a consequence, it can be assumed that group differences in boredom after the primary task could systematically distort performance in the secondary task, and these effects could be falsely interpreted as evidence either in favor of or against the ego depletion effect.

\section{Limitations and Further Considerations}

Our study has methodological limitations that should be taken into account. First, future 
research might use different self-control demanding tasks to examine the robustness of our findings. For instance, tasks other than the transcription task might give rise to levels of boredom that vary as a function of task demands. Similarly, it would be interesting to investigate the role of boredom in versions of the Stroop task with higher motivational or emotional intensity (e.g., using affective rather than lexical stimuli). Second, our sample consisted of Mturk workers, which raises the question of whether our results generalize to other samples as well. Third, we focused on measuring boredom along with common manipulation checks of self-control (i.e., effort, difficulty, frustration, and tiredness). In future research, boredom should be measured along with additional motivational (e.g., amotivation, disinterest) and attentional processes (e.g., distraction, mind-wandering) to better tease apart the unique contributions boredom makes in the domain of self-control performance. Moreover, to investigate the determinants of boredom arising in self-control tasks, not only the perceived difficulty but also the perceived meaning of the task should be assessed (Pekrun et al., 2010; Westgate \& Wilson, 2018). Finally, boredom might be delineated from task-related emotions (e.g., enjoyment, anger; Pekrun, 2006) and experiences (e.g., mind-wandering; Martarelli et al., 2020) that might affect performance.

\section{Conclusion}

Taken together, the present research provides empirical evidence for the notion that a) traditional ego depletion research designs are likely to induce boredom, that b) boredom affects performance in self-control tasks, and that c) experimental manipulations that are designed to vary the self-control demands they impose can also induce different levels of boredom, thereby acting as a potential confound to conclusions drawn from ego depletion studies. Also, this 
highlights the close link between self-control and boredom, not only on the trait level (Bieleke et al., 2021; Struk et al., 2016; Wolff et al., 2020) but also on the state level (Wolff \& Martarelli, 2020). We believe our findings are important for self-control and boredom researchers alike because it suggests that boredom can affect the results of self-control research and perceptions of depletion might likewise affect results from boredom research. 


\section{References}

Baumeister, R. F., Bratslavsky, E., Muraven, M., \& Tice, D. M. (1998). Ego depletion: Is the active self a limited resource? Journal of Personality and Social Psychology, 74(5), 1252-1265. https://doi.org/10.1037/0022-3514.74.5.1252

Bench, S. W., \& Lench, H. C. (2019). Boredom as a seeking state: Boredom prompts the pursuit of novel (even negative) experiences. Emotion, 19(2), 242-254.

https://doi.org/10.1037/emo0000433

Bieleke, M., Martarelli, C., \& Wolff, W. (2021). If-then planning, self-control, and boredom as predictors of adherence to social distancing guidelines: Evidence from a two-wave longitudinal study with a behavioral intervention. PsyArXiv. https://doi.org/10.31234/osf.io/enzbv

Bieleke, M., \& Wolff, W. (in press). It's not a bug, it's boredom: Effortful willpower balances exploitation and exploration. Behavioral and Brain Sciences. Advance online publication. https://doi.org/10.1017/S0140525X20001053

Carter, E. C., \& McCullough, M. E. (2013). Is ego depletion too incredible? Evidence for the overestimation of the depletion effect. Behavioral and Brain Sciences, 36(6), 683-684. https://doi.org/10.1017/S0140525X13000952

Chin, A., Markey, A., Bhargava, S., Kassam, K. S., \& Loewenstein, G. (2017). Bored in the USA: Experience sampling and boredom in everyday life. Emotion, 17(2), 359-368. https://doi.org/10.1037/emo0000232

Csikszentmihalyi, M. (2000). Beyond boredom and anxiety. Jossey-Bass. 
Danckert, J., \& Eastwood, J. D. (2020). Out of my skull. Harvard University Press. https://doi.org/10.4159/9780674247079

Eastwood, J. D., Frischen, A., Fenske, M. J., \& Smilek, D. (2012). The unengaged mind: Defining boredom in terms of attention. Perspectives on Psychological Science, 7(5), 482-495. https://doi.org/10.1177/1745691612456044

Geana, A., Wilson, R., Daw, N., \& Cohen, J. (2016). Boredom, information-seeking and exploration. In A. Papafragou, D. Grodner, D. Mirman, \& J. C. Trueswell (Eds.), Proceedings of the 38th annual conference of the Cognitive Science Society (pp. 1751-1756). Cognitive Science Society.

Giboin, L.-S., \& Wolff, W. (2019). The effect of ego depletion or mental fatigue on subsequent physical endurance performance: A meta-analysis. Performance Enhancement \& Health, 7(12), 100150. https://doi.org/10.1016/j.peh.2019.100150

Gomez-Ramirez, J., \& Costa, T. (2017). Boredom begets creativity: A solution to the exploitationexploration trade-off in predictive coding. Bio Systems, 162, 168-176. https://doi.org/10.1016/j.biosystems.2017.04.006

Hagger, M. S., Chatzisarantis, N. L. D., Alberts, H., Anggono, C. O., Batailler, C., Birt, A. R., Brand, R., Brandt, M. J., Brewer, G., Bruyneel, S., Calvillo, D. P., Campbell, W. K., Cannon, P. R., Carlucci, M., Carruth, N. P., Cheung, T., Crowell, A., Ridder, D. T. D. de, Dewitte, S., . . Zwienenberg, M. (2016). A multilab preregistered replication of the ego-depletion effect. Perspectives on Psychological Science, 11(4), 546-573.

https://doi.org/10.1177/1745691616652873 
Hagger, M. S., Wood, C., Stiff, C., \& Chatzisarantis, N. L. D. (2010). Ego depletion and the strength model of self-control: A meta-analysis. Psychological Bulletin, 136(4), 495-525. https://doi.org/10.1037/a0019486

Hunter, A., \& Eastwood, J. D. (2018). Does state boredom cause failures of attention? Examining the relations between trait boredom, state boredom, and sustained attention. Experimental Brain Research, 236(9), 2483-2492. https://doi.org/10.1007/s00221-016-4749-7

Inzlicht, M., \& Schmeichel, B. J. (2012). What is ego depletion? Toward a mechanistic revision of the resource model of self-control. Perspectives on Psychological Science, 7(5), 450-463. https://doi.org/10.1177/1745691612454134

Lee, N., Chatzisarantis, N., \& Hagger, M. S. (2016). Adequacy of the sequential-task paradigm in evoking ego-depletion and how to improve detection of ego-depleting phenomena. Frontiers in Psychology, 7, 136. https://doi.org/10.3389/fpsyg.2016.00136

Lin, H., Saunders, B., Friese, M., Evans, N. J., \& Inzlicht, M. (2020). Strong effort manipulations reduce response caution: A preregistered reinvention of the ego-depletion paradigm. Psychological Science, 31(5), 531-547. https://doi.org/10.1177/0956797620904990

Martarelli, C. S., Bertrams, A., \& Wolff, W. (2020). A personality trait-based network of boredom, spontaneous and deliberate mind-wandering. Assessment, 1073191120936336. https://doi.org/10.1177/1073191120936336

Milyavskaya, M., Inzlicht, M., Johnson, T., \& Larson, M. J. (2019). Reward sensitivity following boredom and cognitive effort: A high-powered neurophysiological investigation. Neuropsychologia, 123, 159-168. https://doi.org/10.1016/j.neuropsychologia.2018.03.033 
Pekrun, R. (2006). The Control-Value Theory of achievement emotions: Assumptions, corollaries, and implications for educational research and practice. Educational Psychology Review, 18(4), 315-341. https://doi.org/10.1007/s10648-006-9029-9

Pekrun, R., Goetz, T., Daniels, L. M., Stupnisky, R. H., \& Perry, R. P. (2010). Boredom in achievement settings: Exploring control-value antecedents and performance outcomes of a neglected emotion. Journal of Educational Psychology, 102(3), 531-549. https://doi.org/10.1037/a0019243

Schmeichel, B. J., \& Baumeister, R. F. (2010). Effortful attention control. In B. Bruya (Ed.), Effortless attention: A new perspective in the cognitive science of attention and action (pp. 29-49). MIT Press. https://doi.org/10.7551/mitpress/9780262013840.003.0002

Struk, A. A., Carriere, J. S. A., Cheyne, J. A., \& Danckert, J. (2017). A Short Boredom Proneness Scale. Assessment, 24(3), 346-359. https://doi.org/10.1177/1073191115609996

Struk, A. A., Scholer, A. A., \& Danckert, J. (2016). A self-regulatory approach to understanding boredom proneness. Cognition \& Emotion, 30, 1388-1401. https://doi.org/10.1080/02699931.2015.1064363

Vohs, K. D., \& Heatherton, T. F. (2000). Self-regulatory failure: A resource-depletion approach. Psychological Science, 11(3), 249-254. https://doi.org/10.1111/1467-9280.00250

Wagenmakers, E.-J., van der Maas, H. L. J., \& Grasman, R. P. P. P. (2007). An EZ-diffusion model for response time and accuracy. Psychonomic Bulletin \& Review, 14(1), 3-22. https://doi.org/10.3758/bf03194023 
Westgate, E. C., \& Wilson, T. D. (2018). Boring thoughts and bored minds: The MAC model of boredom and cognitive engagement. Psychological Review, 125(5), 689-713. https://doi.org/10.1037/rev0000097

Wolff, W., Baumann, L., \& Englert, C. (2018). Self-reports from behind the scenes: Questionable research practices and rates of replication in ego depletion research. PLoS One, 13(6), e0199554. https://doi.org/10.1371/journal.pone.0199554

Wolff, W., \& Martarelli, C. S. (2020). Bored into depletion? Toward a tentative integration of perceived self-control exertion and boredom as guiding signals for goal-directed behavior. Perspectives on Psychological Science. Advance online publication. https://doi.org/10.1177/1745691620921394

Wolff, W., Martarelli, C. S., Schüler, J., \& Bieleke, M. (2020). High boredom proneness and low trait self-control impair adherence to social distancing guidelines during the COVID-19 pandemic. International Journal of Environmental Research and Public Health, 17(15). https://doi.org/10.3390/ijerph17155420

Wolff, W., Sieber, V., Bieleke, M., \& Englert, C. (2019). Task duration and task order do not matter: No effect on self-control performance. Psychological Research. Advance online publication. https://doi.org/10.1007/s00426-019-01230-1 


\section{Figure 1}

The Effects of Block and Instruction on the Perception of the Stroop Task
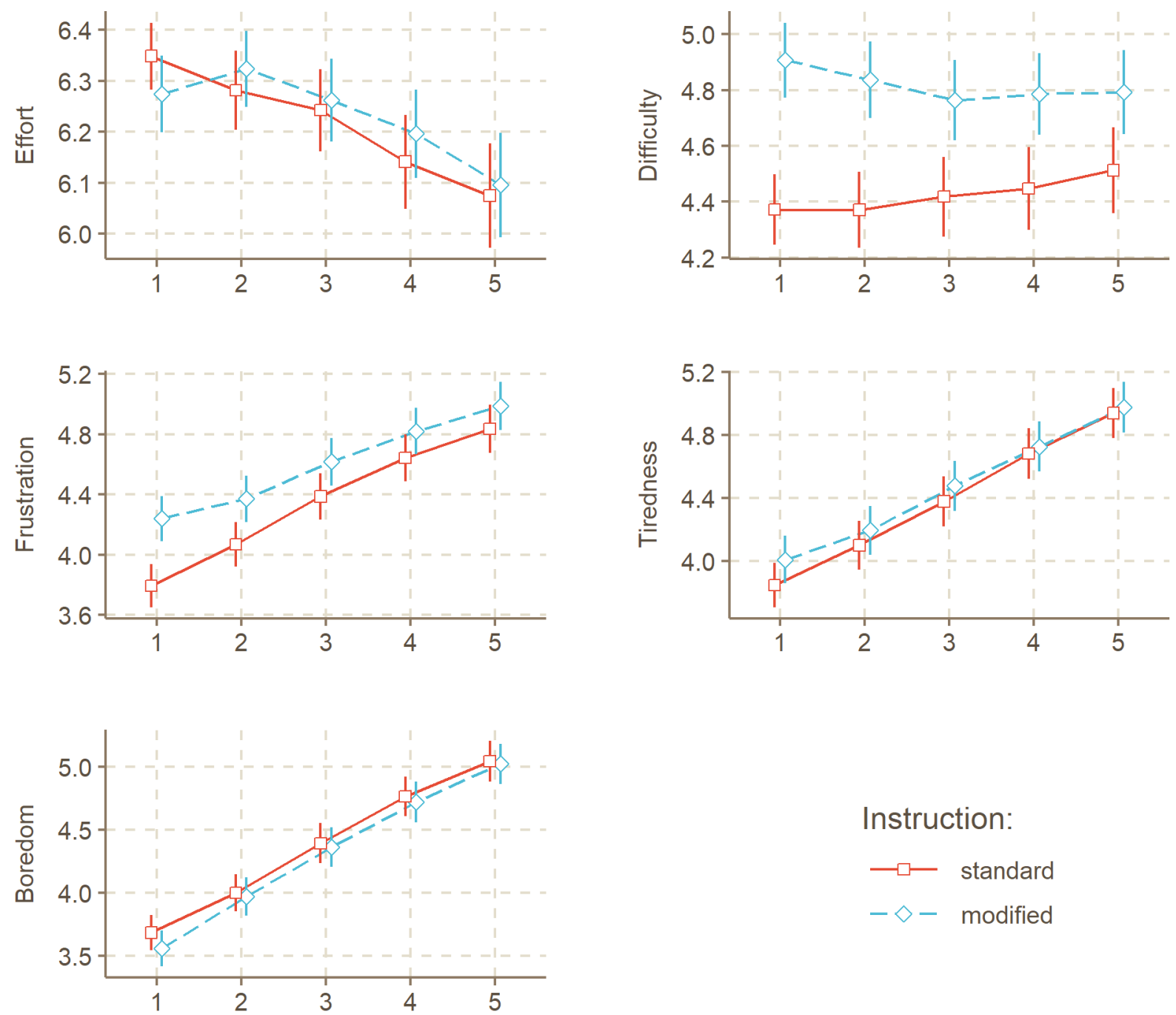

Instruction:

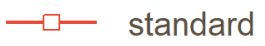

$-\diamond-$ modified

Block

Note. Error bars indicate $95 \%$ confidence intervals. 


\section{Figure 2}

The Effects of Block, Instruction, and Stimulus on Performance in the Stroop task
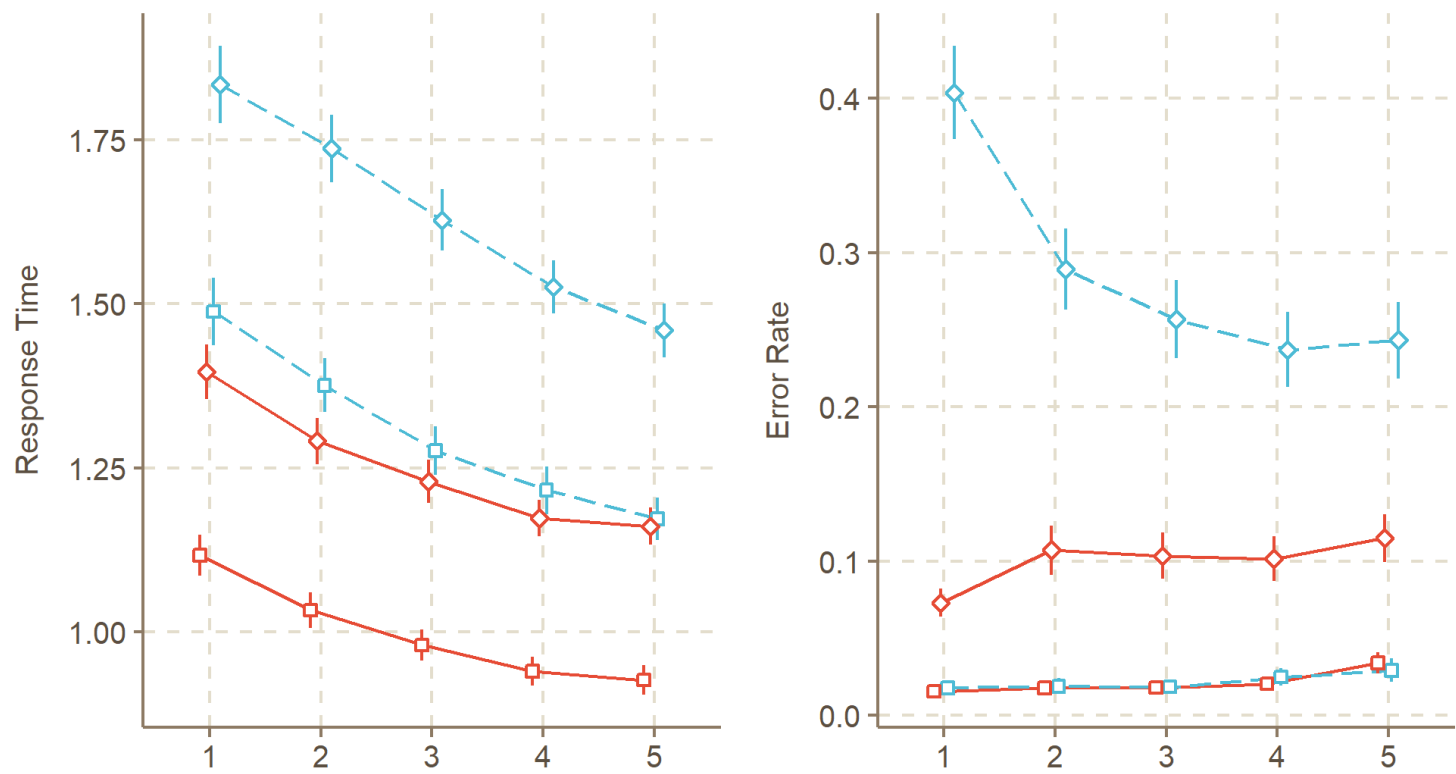

Block

Stimulus:

a congruent

$\diamond \quad$ incongruent
Instruction:

standard

- modified

Note. Error bars indicate $95 \%$ confidence intervals. 


\title{
Trajectories of Boredom in Self-Control Demanding Tasks
}

\author{
Supplementary Materials
}

\section{Details on participant recruitment, demographic characteristics, and data exclusions}

A total of 1,224 respondents were initially recruited via Amazon MTurk (eligibility criteria: US citizenship, approval rate $\geq 90 \%$, track record $\geq 100$ HITs, Buhrmester et al., 2011) and Turk Prime (Litman et al., 2017), 187 (15.3\%) of whom dropped out during the initial instructions. Of the remaining 1,037 participants, we excluded $82(7.9 \%)$ because they participated twice in the transcription task and another $48(4.6 \%)$ because of colorblindness, leaving 907 participants eligible for the Stroop task. Of these, 188 (20.7\%) participants dropped out at the transition between the transcription and the Stroop task. This dropout was evenly distributed across the six conditions, $X^{2}(2, N=907)=1.86, p=.395$, and does therefore not interfere with our analyses. The resulting final sample included 719 participants. They received between $\$ 2.00$ and $\$ 2.60$ depending on the duration of the transcription task. Most participants indicated a bachelor's degree (37.8\%) as their highest level of schooling, followed by college (23.1\%), high school (11.7\%), associate (11.3\%), and master's degrees (8.2\%). With regard to employment, where multiple answers were possible, most participants reported to be working (67.9\%), to be retired (16.6\%), or to be unable to work (13.8\%). Some indicated to be unemployed (3.5\%) or to be looking for work $(6.3 \%)$, to be homemaker (6.2\%), in the military (4.8\%), or student (3.8\%). For further details, see Table S1.

In the analysis of the Stroop task, we excluded data from 26 (3.6\%) participants with an error rate exceeding $50 \%$. We further excluded data from 19 participants (2.6\%) because their error rate exceeded the average error rate of the remaining participants by more than 3 standard deviations. For response times, we excluded trials in which response times were faster than 0.2 seconds or slower than 10 seconds. We further excluded trials in which response times deviated by more than 3 standard deviations from a participant's average response time under standard versus modified Stroop instructions. The sample size for these analyses was therefore reduced to $N=674$, which was still larger than the planned minimum sample size and allowed us to detect small-to-medium effects as intended ( $f=$ $.152)$. 


\section{Table S1}

Detailed Participant Characteristics

\begin{tabular}{lcc}
\hline Characteristic & $n$ & $\%$ \\
\hline Gender & 358 & 52.49 \\
Men & 323 & 47.36 \\
Women & 1 & 0.14 \\
Other & & \\
English proficiency & 650 & 95.31 \\
Native speaker & 32 & 4.69 \\
Fluent & 0 & 0 \\
Basic knowledge & 0 & 0 \\
Little/None & &
\end{tabular}

\section{Highest degree}

No schooling completed

Nursery school to 8 th grade

$\begin{array}{cc}0 & 0 \\ 0 & 0 \\ 9 & 1.32 \\ 80 & 11.73 \\ 158 & 23.17 \\ 30 & 4.40 \\ 77 & 11.29 \\ 258 & 37.83 \\ 59 & 8.65 \\ 8 & 1.17 \\ 3 & 0.44\end{array}$

Some high school, no diploma

High school graduate or equivalent

Trade/technical/vocational training

Associate degree

Bachelor's degree

Master's degree

Professional degree

0.44

\section{Current employment status ${ }^{b}$}

working

student (high school)

student (university or college)

3

0.44

apprentice/trainee

0.29

unemployed

retired

house husband/housewife

0.29

Employed for wages

0.15

Self-employed 


\section{Table S1 (continued)}

Detailed Participant Characteristics

\begin{tabular}{lcc}
\hline Characteristic & $n$ & $\%$ \\
\hline Current employment status $^{\mathbf{b}}$ & 3 & 0.44 \\
Out of work, not currently looking for work & 42 & 6.16 \\
A homemaker & 26 & 3.81 \\
A student & 33 & 4.84 \\
Military & 0 & 0 \\
retired & 94 & 13.78 \\
unable to work & & \\
Ethnicity & 507 & 74.34 \\
White & 45 & 6.60 \\
Hispanic or Latino & 66 & 9.68 \\
Black or African American & 6 & 0.88 \\
Native American or American Ind. & 44 & 6.45 \\
Asian / Pacific Islander & 14 & 2.05 \\
Other & & \\
\hline
\end{tabular}

Note. Percentages do not always add up to 100 because of rounding errors. 37 participants did not respond to the demographic questions.

${ }^{b}$ Participants could choose more than one answer 


\section{Drift-diffusion modeling}

The drift-diffusion model approach (Ratcliff \& Rouder, 1998) permits inferences about cognitive processes based on observed response time distributions and the accuracy of responses. The core assumption is that noisy information about a stimulus (e.g., a word presented on the screen) is accumulated over time until a response threshold is reached and a respective response (e.g., correct/incorrect) is initiated. The response latencies and errors can then be used to estimate four parameters that characterize this evidence accumulation process (for details, see Voss et al., 2013):

(1) The direction and the speed of the process (drift rate parameter), which is determined by the difficulty of the task and individual abilities.

(2) The threshold of the process (boundary parameter), which indicates how much evidence for a response is collected before the response is initiated.

(3) The starting point of the process (starting point parameter), which describes whether evidence accumulation is a priori biased towards a certain response.

(4) Duration of other processes (non-decisional parameter), which describes the time it takes to encode the information and to execute the response.

The following graph summarizes the drift diffusion model and shows a schematic example of the four parameters. The horizontal axis represents response time (i.e., the sum of decision and non-decision time) and the vertical axis represents evidence for the correct vs. incorrect response. Note that we set the starting point to 0 (i.e., unbiased) because there cannot be an a priori bias for the correct or incorrect response and to follow the approach by Wagenmakers et al. (2007), which we used to estimate the remaining latent parameters (i.e., drift rate, boundary parameter, non-decision time). The figure shows two exemplary drift rates: In the blue example, evidence accumulation is comparatively slow and directed towards the correct response. In the orange example, evidence accumulation is faster (steeper slope) and directed towards the incorrect response.

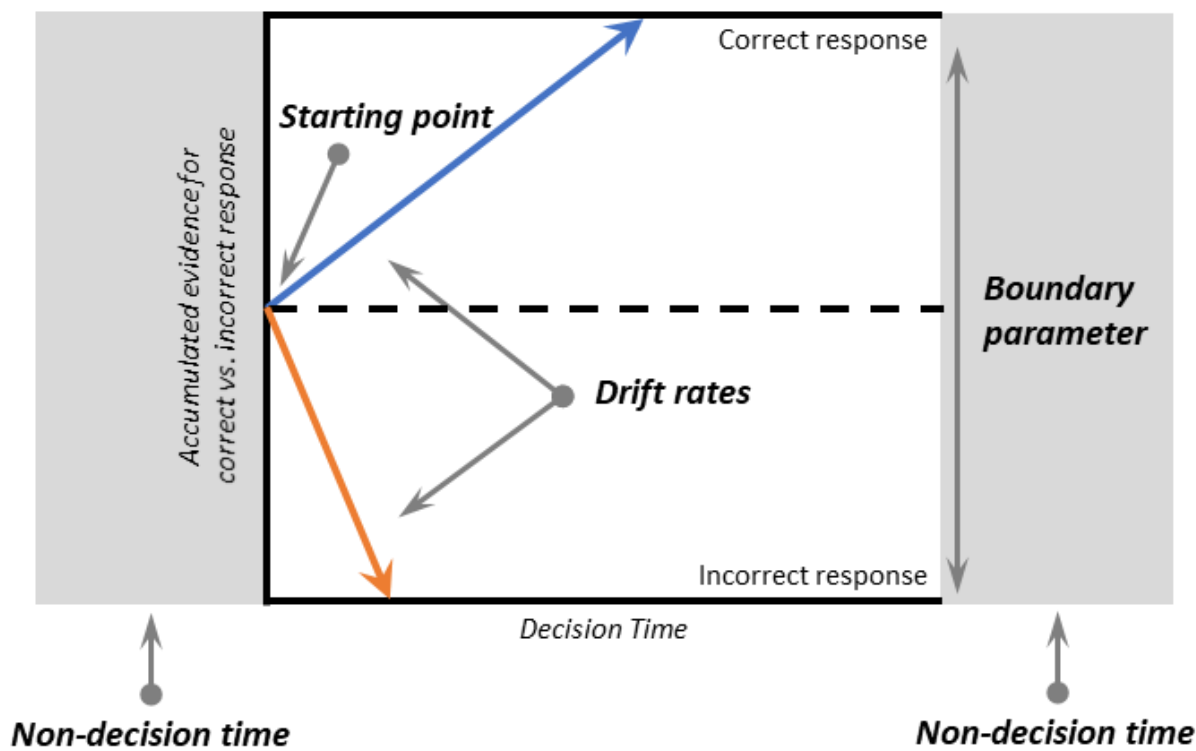




\section{Table S2}

Means, Standard Deviations, and Correlations of Perceptions Related to Self-Control and Boredom in the Transcription and the Stroop Task, and their Correlations with Trait Boredom

\begin{tabular}{|c|c|c|c|c|c|c|c|}
\hline Variable & $M$ & $S D$ & 1 & 2 & 3 & 4 & Boredom (Trait) \\
\hline \multicolumn{8}{|l|}{ Transcription Task } \\
\hline 1. Effort & 6.27 & 0.92 & & & & & $\begin{array}{c}-.14 \\
{[-.21,-.07]}\end{array}$ \\
\hline 2. Difficulty & 4.37 & 1.89 & $\begin{array}{c}. \mathbf{1 3} \\
{[.06, .20]}\end{array}$ & & & & $\begin{array}{c}. \mathbf{1 7} \\
{[.09, .24]}\end{array}$ \\
\hline 3. Frustration & 3.63 & 1.86 & $\begin{array}{c}.02 \\
{[-.05, .10]}\end{array}$ & $\begin{array}{c}.59 \\
{[.54, .64]}\end{array}$ & & & $\begin{array}{c}.23 \\
{[.15, .30]}\end{array}$ \\
\hline 4. Tiredness & 3.72 & 1.86 & $\begin{array}{c}. \mathbf{1 3} \\
{[.06, .20]}\end{array}$ & $\begin{array}{c}.49 \\
{[.43, .54]}\end{array}$ & $\begin{array}{c}.64 \\
{[.59, .68]}\end{array}$ & & $\begin{array}{c}.21 \\
{[.14, .28]}\end{array}$ \\
\hline 5. Boredom (State) & 4.63 & 1.90 & $\begin{array}{c}-.10 \\
{[-.17,-.03]}\end{array}$ & $\begin{array}{c}. \mathbf{1 1} \\
{[.04, .19]}\end{array}$ & $\begin{array}{c}.32 \\
{[.26, .39]}\end{array}$ & $\begin{array}{c}.27 \\
{[.20, .33]}\end{array}$ & $\begin{array}{c}.06 \\
{[-.02, .13]}\end{array}$ \\
\hline \multicolumn{8}{|l|}{ Stroop Task } \\
\hline 1. Effort & 6.22 & 0.90 & & & & & $\begin{array}{c}-.17 \\
{[-.25,-.10]}\end{array}$ \\
\hline 2. Difficulty & 4.61 & 1.64 & $\begin{array}{c}.29 \\
{[.22, .36]}\end{array}$ & & & & $\begin{array}{c}. \mathbf{1 9} \\
{[.11, .26]}\end{array}$ \\
\hline 3. Frustration & 4.48 & 1.78 & $\begin{array}{c}.17 \\
{[.09, .24]}\end{array}$ & $\begin{array}{c}.78 \\
{[.75, .81]}\end{array}$ & & & $\begin{array}{c}.25 \\
{[.17, .32]}\end{array}$ \\
\hline 4. Tiredness & 4.45 & 1.84 & $\begin{array}{c}. \mathbf{1 8} \\
{[.11, .25]}\end{array}$ & $\begin{array}{c}.68 \\
{[.64, .72]}\end{array}$ & $\begin{array}{c}.79 \\
{[.76, .82]}\end{array}$ & & $\begin{array}{c}.27 \\
{[.19, .34]}\end{array}$ \\
\hline 5. Boredom (State) & 4.38 & 1.79 & $\begin{array}{c}-.16 \\
{[-.24,-.09]}\end{array}$ & $\begin{array}{c}.27 \\
{[.20, .34]}\end{array}$ & $\begin{array}{c}.49 \\
{[.43, .54]}\end{array}$ & $\begin{array}{c}.49 \\
{[.43, .54]}\end{array}$ & $\begin{array}{c}.22 \\
{[.14, .29]}\end{array}$ \\
\hline
\end{tabular}

Note. Values in square brackets indicate the $95 \%$ confidence interval for each correlation. Sample sizes range from $N=642$ to $N=719$. Correlations in the Stroop task were averaged across blocks and instructions.

Coefficients that are significant at $p<.05$ are highlighted in boldface

\section{Curvilinear Association Between Boredom and Difficulty}

Theoretical accounts of the determinants of boredom assume that boredom arises when difficulty is either low (underchallenge) or high (overchallenge). To test this prediction, we conducted a multiple regression analysis in which we regressed boredom simultaneously on the linear and the quadratic effect of difficulty (after mean-centering). The linear term was significant in both the transcription task, $\beta=0.131, S E=0.040, p=.001$, and the Stroop task, $\beta=0.344, S E=0.045, p<.001$. And while the quadratic term was not significant in the transcription task, $\beta=0.027, S E=0.024, p=.263$, it was indeed significant in the Stroop task, $\beta=0.074, S E=0.025, p=.004$. Closer inspection of the association between boredom and difficulty in the Stroop task indicated that boredom was similarly pronounced at low and intermediate levels of difficulty but much more pronounced at high levels of difficulty, giving rise to the significant quadratic term. 


\section{Development of Associations of Boredom With Effort, Difficulty, Frustration, and Tiredness in the Stroop Task}

As we measured boredom, as well as effort, difficulty, frustration, and tiredness repeatedly during the Stroop task, we checked how the association between boredom and the remaining variables developed over the five blocks. We observed that the association between boredom and effort decreased over the five blocks (-.23/-.17/-.14/-.13/-.07), whereas all other associations increased (difficulty: .12/.24/.25/.28/.29; frustration: $.34 / .42 / .46 / .48 / .53$; tiredness: .37/.43/.47/.50/.52). A closer look at the data suggests that individuals who reported higher levels of boredom invested rather low levels of effort throughout the task, while they perceived the task as increasingly difficult, frustrating, and tiresome. In contrast, individuals who reported lower levels of boredom showed initially higher but then declining levels of effort, while they perceived the task as decreasingly difficult, frustrating, and tiresome. As a consequence, the levels of effort converged, while the levels of difficulty, frustration, and tiredness diverged, explaining the observed changes in the association between these variables and boredom.

\section{Table S3}

Means and Standard Deviations for Subjective Perceptions During the Transcription Task

\begin{tabular}{|c|c|c|c|c|c|c|c|c|c|c|}
\hline \multirow[t]{2}{*}{ Condition } & \multicolumn{2}{|c|}{ Effort } & \multicolumn{2}{|c|}{ Difficulty } & \multicolumn{2}{|c|}{ Frustration } & \multicolumn{2}{|c|}{ Tiredness } & \multicolumn{2}{|c|}{ Boredom } \\
\hline & $M$ & $S D$ & $M$ & $S D$ & $M$ & $S D$ & $M$ & $S D$ & $M$ & $S D$ \\
\hline \multicolumn{11}{|l|}{ Time: 2 Minutes } \\
\hline Demand: HighH & 6.23 & 0.96 & 4.81 & 1.61 & 3.64 & 1.69 & 3.49 & 1.65 & 4.45 & 1.81 \\
\hline Demand: Low & 5.99 & 0.97 & 3.41 & 1.85 & 3.27 & 1.84 & 2.94 & 1.77 & 4.52 & 1.74 \\
\hline \multicolumn{11}{|l|}{ Time: 4 Minutes } \\
\hline Demand: High & 6.27 & 1.05 & 5.21 & 1.40 & 4.02 & 1.82 & 4.02 & 1.86 & 4.57 & 2.00 \\
\hline Demand: Low & 6.30 & 0.79 & 3.71 & 1.86 & 3.31 & 1.90 & 3.47 & 1.73 & 4.78 & 1.92 \\
\hline \multicolumn{11}{|l|}{ Time: 8 Minutes } \\
\hline Demand: High & 6.48 & 0.69 & 5.39 & 1.50 & 4.12 & 1.82 & 4.45 & 1.86 & 4.78 & 1.95 \\
\hline Demand: Low & 6.33 & 0.93 & 3.64 & 2.01 & 3.39 & 1.95 & 3.93 & 1.93 & 4.68 & 1.98 \\
\hline
\end{tabular}




\section{Table S4}

ANOVA Results for Subjective Perceptions During the Transcription Task

\begin{tabular}{|c|c|c|c|c|c|c|c|c|c|c|c|c|c|c|c|c|}
\hline \multirow[b]{2}{*}{ Effect } & \multirow[b]{2}{*}{$d f$} & \multicolumn{3}{|c|}{ Effort } & \multicolumn{3}{|c|}{ Difficulty } & \multicolumn{3}{|c|}{ Frustration } & \multicolumn{3}{|c|}{ Tiredness } & \multicolumn{3}{|c|}{ Boredom } \\
\hline & & $F$ & $\eta_{G}^{2}$ & $p$ & $F$ & $\eta_{G}^{2}$ & $p$ & $F$ & $\eta_{G}^{2}$ & $p$ & $F$ & $\eta_{G}^{2}$ & $p$ & $F$ & $\eta_{G}^{2}$ & $p$ \\
\hline D & 1,713 & 3.09 & .004 & .079 & 146.39 & .170 & $<.001$ & 19.45 & .027 & $<.001$ & 16.03 & .022 & $<.001$ & 0.18 & $<.001$ & .668 \\
\hline $\mathrm{T}$ & 2,713 & 6.25 & .017 & .002 & 3.91 & .011 & .020 & 1.68 & .004 & .188 & 17.52 & .047 & $<.001$ & 1.12 & .003 & .328 \\
\hline$D \times T$ & 2,713 & 1.33 & .003 & .266 & 2.95 & .002 & .501 & 0.71 & .002 & .494 & 0.00 & $<.001$ & .997 & 0.42 & .001 & .655 \\
\hline
\end{tabular}

Note: $\mathrm{D}=$ Demand, $\mathrm{T}=$ Time. Significant effects $(p<.05)$ are highlighted in boldface. 
Table S5

Means and Standard Deviations for Subjective Perceptions During the Stroop Task (Standard Instructions)

\begin{tabular}{|c|c|c|c|c|c|c|c|c|c|c|}
\hline \multirow[b]{2}{*}{ Block and Condition } & \multicolumn{2}{|c|}{ Effort } & \multicolumn{2}{|c|}{ Difficulty } & \multicolumn{2}{|c|}{ Frustration } & \multicolumn{2}{|c|}{ Tiredness } & \multicolumn{2}{|c|}{ Boredom } \\
\hline & $M$ & $S D$ & $M$ & $S D$ & $M$ & $S D$ & $M$ & $S D$ & $M$ & $S D$ \\
\hline \multicolumn{11}{|l|}{ Block 1} \\
\hline \multicolumn{11}{|l|}{ Time: 2 Minutes } \\
\hline Demand: Low & 6.35 & 0.89 & 4.28 & 1.68 & 3.73 & 1.79 & 3.81 & 1.86 & 3.52 & 1.71 \\
\hline Demand: High & 6.34 & 0.85 & 4.60 & 1.58 & 3.78 & 1.84 & 4.04 & 1.71 & 3.67 & 1.79 \\
\hline \multicolumn{11}{|l|}{ Time: 4 Minutes } \\
\hline Demand: Low & 6.30 & 1.00 & 4.19 & 1.77 & 3.61 & 1.93 & 3.56 & 1.95 & 3.95 & 1.82 \\
\hline Demand: High & 6.41 & 0.80 & 4.48 & 1.56 & 3.92 & 1.88 & 3.74 & 1.84 & 3.66 & 1.79 \\
\hline \multicolumn{11}{|l|}{ Time: 8 Minutes } \\
\hline Demand: Low & 6.41 & 0.73 & 4.36 & 1.87 & 3.87 & 1.98 & 3.79 & 1.84 & 3.43 & 1.87 \\
\hline Demand: High & 6.28 & 0.91 & 4.31 & 1.59 & 3.86 & 1.84 & 4.17 & 1.85 & 3.89 & 1.97 \\
\hline \multicolumn{11}{|l|}{ Block 2} \\
\hline \multicolumn{11}{|l|}{ Time: 2 Minutes } \\
\hline Demand: Low & 6.26 & 1.06 & 4.27 & 1.78 & 3.87 & 1.92 & 4.01 & 2.03 & 3.89 & 1.85 \\
\hline Demand: High & 6.27 & 1.06 & 4.53 & 1.74 & 4.14 & 1.88 & 4.26 & 1.91 & 4.05 & 1.92 \\
\hline \multicolumn{11}{|l|}{ Time: 4 Minutes } \\
\hline Demand: Low & 6.37 & 0.97 & 4.32 & 1.91 & 3.94 & 2.11 & 3.87 & 2.19 & 4.33 & 1.99 \\
\hline Demand: High & 6.28 & 1.15 & 4.49 & 1.70 & 4.44 & 1.95 & 4.15 & 2.01 & 3.99 & 1.95 \\
\hline \multicolumn{11}{|l|}{ Time: 8 Minutes } \\
\hline Demand: Low & 6.26 & 0.96 & 4.24 & 1.88 & 3.96 & 1.91 & 4.09 & 2.02 & 3.80 & 2.08 \\
\hline Demand: High & 6.25 & 0.94 & 4.37 & 1.80 & 4.05 & 1.88 & 4.23 & 1.99 & 3.93 & 1.95 \\
\hline \multicolumn{11}{|l|}{ Block 3} \\
\hline \multicolumn{11}{|l|}{ Time: 2 Minutes } \\
\hline Demand: Low & 6.18 & 1.06 & 4.25 & 1.91 & 4.13 & 2.07 & 4.16 & 2.08 & 4.32 & 2.01 \\
\hline Demand: High & 6.17 & 1.17 & 4.62 & 1.83 & 4.59 & 1.92 & 4.57 & 1.99 & 4.43 & 2.05 \\
\hline \multicolumn{11}{|l|}{ Time: 4 Minutes } \\
\hline Demand: Low & 6.26 & 1.14 & 4.23 & 1.92 & 4.07 & 2.15 & 4.12 & 2.23 & 4.58 & 2.12 \\
\hline Demand: High & 6.28 & 1.09 & 4.64 & 1.75 & 4.69 & 1.97 & 4.38 & 2.0 & 4.34 & 2.04 \\
\hline \multicolumn{11}{|l|}{ Time: 8 Minutes } \\
\hline Demand: Low & 6.30 & 1.03 & 4.25 & 2.01 & 4.34 & 2.00 & 4.44 & 2.09 & 4.23 & 2.22 \\
\hline Demand: High & 6.27 & 0.88 & 4.50 & 1.91 & 4.49 & 2.07 & 4.60 & 2.02 & 4.48 & 2.14 \\
\hline Block 4 & & & & & & & & & & \\
\hline Time: 2 Minutes & & & & & & & & & & \\
\hline Demand: Low & 6.15 & 1.26 & 4.37 & 2.10 & 4.47 & 2.09 & 4.62 & 2.15 & 4.84 & 2.02 \\
\hline Demand: High & 6.05 & 1.24 & 4.75 & 1.75 & 4.79 & 1.98 & 4.82 & 1.94 & 4.85 & 2.03 \\
\hline Time: 4 Minutes & & & & & & & & & & \\
\hline Demand: Low & 6.11 & 1.23 & 4.19 & 2.02 & 4.50 & 2.24 & 4.39 & 2.32 & 4.85 & 2.16 \\
\hline Demand: High & 6.20 & 1.27 & 4.64 & 1.85 & 4.73 & 2.05 & 4.51 & 2.09 & 4.70 & 2.07 \\
\hline Time: 8 Minutes & & & & & & & & & & \\
\hline Demand: Low & 6.12 & 1.30 & 4.31 & 1.98 & 4.68 & 2.01 & 4.91 & 2.04 & 4.50 & 2.15 \\
\hline Demand: High & 6.21 & 0.97 & 4.41 & 1.97 & 4.67 & 2.04 & 4.87 & 2.06 & 4.86 & 2.03 \\
\hline Block 5 & & & & & & & & & & \\
\hline Time: 2 Minutes & & & & & & & & & & \\
\hline Demand: Low & 6.11 & 1.29 & 4.35 & 2.14 & 4.68 & 2.07 & 4.84 & 2.10 & 5.19 & 2.07 \\
\hline Demand: High & 5.94 & 1.46 & 4.71 & 1.96 & 4.85 & 2.16 & 4.96 & 2.14 & 5.05 & 2.10 \\
\hline Time: 4 Minutes & & & & & & & & & & \\
\hline Demand: Low & 6.13 & 1.29 & 4.32 & 2.08 & 4.73 & 2.24 & 4.49 & 2.29 & 5.14 & 2.11 \\
\hline Demand: High & 6.16 & 1.33 & 4.75 & 1.86 & 4.90 & 2.01 & 4.89 & 1.99 & 4.96 & 2.05 \\
\hline Time: 8 Minutes & & & & & & & & & & \\
\hline Demand: Low & 6.01 & 1.56 & 4.37 & 2.13 & 5.04 & 1.95 & 5.31 & 1.88 & 4.83 & 2.27 \\
\hline Demand: High & 6.09 & 1.17 & 4.56 & 1.99 & 4.81 & 2.13 & 5.17 & 1.97 & 5.10 & 2.06 \\
\hline
\end{tabular}


Table S6

Means and Standard Deviations for Subjective Perceptions During the Stroop Task (Modified Instructions)

\begin{tabular}{|c|c|c|c|c|c|c|c|c|c|c|}
\hline \multirow[b]{2}{*}{ Block and Condition } & \multicolumn{2}{|c|}{ Effort } & \multicolumn{2}{|c|}{ Difficulty } & \multicolumn{2}{|c|}{ Frustration } & \multicolumn{2}{|c|}{ Tiredness } & \multicolumn{2}{|c|}{ Boredom } \\
\hline & $M$ & $S D$ & $M$ & $S D$ & $M$ & $S D$ & $M$ & $S D$ & $M$ & $S D$ \\
\hline \multicolumn{11}{|l|}{ Block 1} \\
\hline \multicolumn{11}{|l|}{ Time: 2 Minutes } \\
\hline Demand: Low & 6.23 & 0.99 & 4.65 & 1.77 & 4.06 & 1.90 & 3.93 & 1.92 & 3.45 & 1.79 \\
\hline Demand: High & 6.23 & 1.03 & 5.25 & 1.60 & 4.38 & 1.98 & 4.21 & 1.85 & 3.62 & 1.86 \\
\hline \multicolumn{11}{|l|}{ Time: 4 Minutes } \\
\hline Demand: Low & 6.30 & 0.97 & 4.80 & 1.95 & 4.15 & 2.06 & 3.86 & 2.16 & 3.72 & 1.95 \\
\hline Demand: High & 6.36 & 0.94 & 4.88 & 1.70 & 4.41 & 1.98 & 3.94 & 1.99 & 3.60 & 1.89 \\
\hline \multicolumn{11}{|l|}{ Time: 8 Minutes } \\
\hline Demand: Low & 6.25 & 1.04 & 4.93 & 1.82 & 4.27 & 2.00 & 3.99 & 2.03 & 3.35 & 1.91 \\
\hline Demand: High & 6.28 & 1.02 & 4.93 & 1.77 & 4.16 & 1.98 & 4.15 & 1.91 & 3.62 & 1.93 \\
\hline \multicolumn{11}{|l|}{ Block 2} \\
\hline \multicolumn{11}{|l|}{ Time: 2 Minutes } \\
\hline Demand: Low & 6.32 & 0.98 & 4.50 & 1.89 & 4.15 & 2.01 & 3.98 & 2.05 & 3.85 & 1.91 \\
\hline Demand: High & 6.34 & 0.94 & 4.98 & 1.79 & 4.35 & 1.99 & 4.35 & 1.98 & 4.04 & 2.05 \\
\hline \multicolumn{11}{|l|}{ Time: 4 Minutes } \\
\hline Demand: Low & 6.39 & 1.00 & 4.80 & 2.01 & 4.22 & 2.26 & 4.00 & 2.22 & 4.25 & 2.09 \\
\hline Demand: High & 6.27 & 1.12 & 5.01 & 1.60 & 4.64 & 2.00 & 4.14 & 1.95 & 3.90 & 1.98 \\
\hline \multicolumn{11}{|l|}{ Time: 8 Minutes } \\
\hline Demand: Low & 6.29 & 1.03 & 4.89 & 1.82 & 4.54 & 1.96 & 4.29 & 2.04 & 3.81 & 2.11 \\
\hline Demand: High & 6.34 & 0.81 & 4.83 & 1.77 & 4.31 & 1.92 & 4.43 & 2.01 & 3.98 & 2.04 \\
\hline \multicolumn{11}{|l|}{ Block 3} \\
\hline \multicolumn{11}{|l|}{ Time: 2 Minutes } \\
\hline Demand: Low & 6.26 & 0.97 & 4.42 & 1.88 & 4.32 & 2.08 & 4.23 & 2.13 & 4.41 & 1.91 \\
\hline Demand: High & 6.19 & 1.16 & 4.92 & 1.83 & 4.75 & 1.93 & 4.72 & 1.98 & 4.46 & 2.11 \\
\hline \multicolumn{11}{|l|}{ Time: 4 Minutes } \\
\hline Demand: Low & 6.28 & 1.21 & 4.70 & 2.06 & 4.49 & 2.20 & 4.24 & 2.23 & 4.43 & 2.11 \\
\hline Demand: High & 6.23 & 1.13 & 5.03 & 1.71 & 4.90 & 2.00 & 4.49 & 2.07 & 4.31 & 2.07 \\
\hline \multicolumn{11}{|l|}{ Time: 8 Minutes } \\
\hline Demand: Low & 6.35 & 1.02 & 4.84 & 1.92 & 4.69 & 2.14 & 4.55 & 2.10 & 4.10 & 2.20 \\
\hline Demand: High & 6.27 & 0.96 & 4.66 & 1.93 & 4.53 & 2.13 & 4.64 & 1.99 & 4.48 & 2.08 \\
\hline Block 4 & & & & & & & & & & \\
\hline Time: 2 Minutes & & & & & & & & & & \\
\hline Demand: Low & 6.15 & 1.26 & 4.52 & 2.10 & 4.57 & 2.12 & 4.56 & 2.16 & 4.69 & 2.14 \\
\hline Demand: High & 6.17 & 1.18 & 5.03 & 1.79 & 4.94 & 2.00 & 4.88 & 1.99 & 4.86 & 2.07 \\
\hline Time: 4 Minutes & & & & & & & & & & \\
\hline Demand: Low & 6.23 & 1.13 & 4.51 & 2.12 & 4.68 & 2.21 & 4.47 & 2.26 & 4.88 & 2.18 \\
\hline Demand: High & 6.23 & 1.17 & 4.97 & 1.77 & 4.99 & 1.95 & 4.61 & 2.10 & 4.70 & 2.06 \\
\hline Time: 8 Minutes & & & & & & & & & & \\
\hline Demand: Low & 6.12 & 1.24 & 4.95 & 1.80 & 5.00 & 1.93 & 4.91 & 2.05 & 4.35 & 2.19 \\
\hline Demand: High & 6.28 & 0.85 & 4.72 & 1.91 & 4.72 & 2.01 & 4.94 & 2.02 & 4.83 & 2.06 \\
\hline Block 5 & & & & & & & & & & \\
\hline Time: 2 Minutes & & & & & & & & & & \\
\hline Demand: Low & 6.14 & 1.40 & 4.51 & 2.08 & 4.82 & 2.10 & 4.84 & 2.19 & 5.03 & 2.14 \\
\hline Demand: High & 5.96 & 1.43 & 4.92 & 1.96 & 4.89 & 2.16 & 4.95 & 2.22 & 5.03 & 2.03 \\
\hline Time: 4 Minutes & & & & & & & & & & \\
\hline Demand: Low & 6.14 & 1.29 & 4.69 & 2.16 & 4.90 & 2.22 & 4.68 & 2.25 & 5.13 & 2.13 \\
\hline Demand: High & 6.19 & 1.29 & 5.03 & 1.84 & 5.05 & 1.98 & 4.88 & 1.99 & 5.01 & 2.02 \\
\hline Time: 8 Minutes & & & & & & & & & & \\
\hline Demand: Low & 6.04 & 1.45 & 4.83 & 1.96 & 5.25 & 2.01 & 5.26 & 1.93 & 4.81 & 2.25 \\
\hline Demand: High & 6.09 & 1.26 & 4.77 & 1.90 & 5.01 & 2.11 & 5.27 & 2.00 & 5.13 & 2.07 \\
\hline
\end{tabular}




\section{Table S7}

Results of ANOVA Analyses for Subjective Perceptions During the Stroop Task

\begin{tabular}{|c|c|c|c|c|c|c|c|c|c|c|c|c|c|c|c|c|}
\hline \multirow[b]{2}{*}{ Effect } & \multirow[b]{2}{*}{$d f$} & \multicolumn{3}{|c|}{ Effort } & \multicolumn{3}{|c|}{ Difficulty } & \multicolumn{3}{|c|}{ Frustration } & \multicolumn{3}{|c|}{ Tiredness } & \multicolumn{3}{|c|}{ Boredom } \\
\hline & & $F$ & $\eta_{G}^{2}$ & $p$ & $F$ & $\eta_{G}^{2}$ & $p$ & $F$ & $\eta_{\mathrm{G}}^{2}$ & $p$ & $F$ & $\eta_{G}^{2}$ & $p$ & $F$ & $\eta_{G}^{2}$ & $p$ \\
\hline 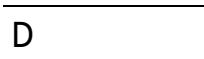 & 1,661 & 0.01 & $<.001$ & .920 & 3.77 & .004 & .053 & 1.36 & .002 & .245 & 1.72 & .002 & .190 & 0.29 & $<.001$ & .588 \\
\hline $\mathrm{T}$ & 2,661 & 0.27 & $<.001$ & .764 & 0.03 & $<.001$ & .972 & 0.21 & $<.001$ & .814 & 1.73 & .004 & .178 & 0.51 & .001 & .603 \\
\hline $\mathrm{D} \times \mathrm{T}$ & 2,661 & 0.07 & $<.001$ & .930 & 0.99 & .002 & .371 & 1.00 & .002 & .368 & 0.14 & $<.001$ & .872 & 1.41 & .003 & .245 \\
\hline I & 1,661 & 0.51 & $<.001$ & .475 & 148.93 & .011 & $<.001$ & 104.29 & .004 & $<.001$ & 20.01 & $<.001$ & $<.001$ & 5.99 & $<.001$ & .015 \\
\hline$D \times I$ & 1,661 & 0.00 & $<.001$ & .979 & 0.74 & $<.001$ & .390 & 2.60 & $<.001$ & .108 & 0.07 & $<.001$ & .789 & 1.52 & $<.001$ & .218 \\
\hline$T \times 1$ & 2,661 & 0.01 & $<.001$ & .993 & 2.62 & $<.001$ & .074 & 0.68 & $<.001$ & .508 & 1.10 & $<.001$ & .334 & 0.13 & $<.001$ & .879 \\
\hline$D \times T \times I$ & 2,661 & 0.66 & $<.001$ & .516 & 3.26 & $<.001$ & .039 & 1.85 & $<.001$ & .158 & 1.39 & $<.001$ & .249 & 0.01 & $<.001$ & .987 \\
\hline B & $4,2644^{a}$ & 16.38 & .006 & $<.001$ & 0.66 & $<.001$ & .556 & 106.05 & .026 & $<.001$ & 151.07 & .033 & $<.001$ & 249.29 & .060 & $<.001$ \\
\hline$D \times B$ & $4,2644^{a}$ & 0.48 & $<.001$ & .678 & 0.56 & $<.001$ & .617 & 2.21 & $<.001$ & .097 & 0.98 & $<.001$ & .392 & 0.47 & $<.001$ & .662 \\
\hline $\mathrm{T} \times \mathrm{B}$ & $8,2644^{a}$ & 0.47 & $<.001$ & .817 & 0.95 & $<.001$ & .450 & 0.66 & $<.001$ & .651 & 1.77 & $<.001$ & .116 & 0.82 & $<.001$ & .534 \\
\hline$D \times T \times B$ & $8,2644^{a}$ & 1.01 & .001 & .414 & 0.71 & $<.001$ & .621 & 0.44 & $<.001$ & .823 & 0.92 & $<.001$ & .476 & 0.44 & $<.001$ & .815 \\
\hline $\mathrm{I} \times \mathrm{B}$ & $4,2644^{b}$ & 3.22 & $<.001$ & .013 & 7.31 & $<.001$ & $<.001$ & 10.98 & $<.001$ & $<.001$ & 2.70 & $<.001$ & .035 & 1.69 & $<.001$ & .157 \\
\hline$D \times 1 \times B$ & $4,2644^{b}$ & 0.59 & $<.001$ & .663 & 0.77 & $<.001$ & .529 & 1.67 & $<.001$ & .163 & 0.75 & $<.001$ & .545 & 0.24 & $<.001$ & .894 \\
\hline $\mathrm{T} \times 1 \times \mathrm{B}$ & $8,2644^{b}$ & 0.49 & $<.001$ & .859 & 0.57 & $<.001$ & .781 & 1.44 & $<.001$ & .184 & 1.40 & $<.001$ & .199 & 1.39 & $<.001$ & .205 \\
\hline$D \times T \times I \times B$ & $8,2644^{b}$ & 0.38 & $<.001$ & .928 & 0.80 & $<.001$ & .593 & 0.82 & $<.001$ & .569 & 1.72 & $<.001$ & .190 & 0.89 & $<.001$ & .516 \\
\hline
\end{tabular}

Note: $\mathrm{D}=$ Demand, $\mathrm{T}=$ Time, $\mathrm{I}=$ Instruction, $\mathrm{B}=\mathrm{Block}$. Significant effects $(p<.05)$ are highlighted in boldface. Uncorrected degrees of freedom are reported but Greenhouse-Geisser corrections $\left(\varepsilon_{\mathrm{GG}}\right)$ were applied when this was indicated by the Mauchly test.

a Effort: $\varepsilon_{\mathrm{GG}}=0.68$, Difficulty: $\varepsilon_{\mathrm{GG}}=0.66$, Frustration: $\varepsilon_{\mathrm{GG}}=0.63$, Tiredness: $\varepsilon_{\mathrm{GG}}=0.63$, Boredom: $\varepsilon_{\mathrm{GG}}=0.61$

${ }^{\mathrm{b}}$ Effort: $\varepsilon_{\mathrm{GG}}=0.96$, Difficulty: $\varepsilon_{\mathrm{GG}}=0.89$, Frustration: $\varepsilon_{\mathrm{GG}}=0.88$, Tiredness: $\varepsilon_{\mathrm{GG}}=0.89$, Boredom: $\varepsilon_{\mathrm{GG}}=0.88$ 


\begin{tabular}{|c|c|c|c|c|c|c|c|c|}
\hline \multirow[b]{3}{*}{ Block and Condition } & \multicolumn{4}{|c|}{ Congruent } & \multicolumn{4}{|c|}{ Incongruent } \\
\hline & \multicolumn{2}{|c|}{ Response Time } & \multicolumn{2}{|c|}{ Error Rate } & \multicolumn{2}{|c|}{ Response Time } & \multicolumn{2}{|c|}{ Error Rate } \\
\hline & $M$ & $S D$ & $M$ & $S D$ & $M$ & $S D$ & $M$ & $S D$ \\
\hline \multicolumn{9}{|l|}{ Block 1} \\
\hline \multicolumn{9}{|l|}{ Time: 2 Minutes } \\
\hline Demand: Low & 1.14 & 0.45 & 0.01 & 0.03 & 1.43 & 0.59 & 0.07 & 0.11 \\
\hline Demand: High & 1.13 & 0.43 & 0.02 & 0.03 & 1.38 & 0.52 & 0.07 & 0.12 \\
\hline \multicolumn{9}{|l|}{ Time: 4 Minutes } \\
\hline Demand: Low & 1.11 & 0.40 & 0.02 & 0.04 & 1.41 & 0.62 & 0.08 & 0.14 \\
\hline Demand: High & 1.11 & 0.37 & 0.01 & 0.03 & 1.38 & 0.50 & 0.08 & 0.13 \\
\hline \multicolumn{9}{|l|}{ Time: 8 Minutes } \\
\hline Demand: Low & 1.09 & 0.43 & 0.02 & 0.03 & 1.36 & 0.51 & 0.07 & 0.10 \\
\hline Demand: High & 1.12 & 0.38 & 0.01 & 0.02 & 1.42 & 0.52 & 0.07 & 0.12 \\
\hline \multicolumn{9}{|l|}{ Block 2} \\
\hline \multicolumn{9}{|l|}{ Time: 2 Minutes } \\
\hline Demand: Low & 1.05 & 0.38 & 0.02 & 0.04 & 1.29 & 0.46 & 0.06 & 0.09 \\
\hline Demand: High & 1.03 & 0.35 & 0.01 & 0.02 & 1.31 & 0.51 & 0.11 & 0.22 \\
\hline \multicolumn{9}{|l|}{ Time: 4 Minutes } \\
\hline Demand: Low & 1.04 & 0.36 & 0.02 & 0.04 & 1.29 & 0.51 & 0.14 & 0.26 \\
\hline Demand: High & 1.03 & 0.39 & 0.02 & 0.04 & 1.27 & 0.45 & 0.11 & 0.22 \\
\hline \multicolumn{9}{|l|}{ Time: 8 Minutes } \\
\hline Demand: Low & 0.99 & 0.37 & 0.02 & 0.03 & 1.22 & 0.43 & 0.10 & 0.20 \\
\hline Demand: High & 1.07 & 0.30 & 0.02 & 0.03 & 1.37 & 0.45 & 0.11 & 0.22 \\
\hline \multicolumn{9}{|l|}{ Block 3} \\
\hline \multicolumn{9}{|l|}{ Time: 2 Minutes } \\
\hline Demand: Low & 0.99 & 0.33 & 0.02 & 0.03 & 1.19 & 0.36 & 0.07 & 0.12 \\
\hline Demand: High & 0.98 & 0.31 & 0.02 & 0.03 & 1.22 & 0.47 & 0.09 & 0.19 \\
\hline \multicolumn{9}{|l|}{ Time: 4 Minutes } \\
\hline Demand: Low & 0.97 & 0.31 & 0.02 & 0.04 & 1.22 & 0.43 & 0.13 & 0.25 \\
\hline Demand: High & 0.97 & 0.29 & 0.02 & 0.03 & 1.22 & 0.37 & 0.09 & 0.16 \\
\hline Time: 8 Minutes & & & & & & & & \\
\hline Demand: Low & 0.95 & 0.35 & 0.02 & 0.04 & 1.19 & 0.39 & 0.14 & 0.24 \\
\hline Demand: High & 1.01 & 0.32 & 0.02 & 0.03 & 1.34 & 0.52 & 0.10 & 0.18 \\
\hline Block 4 & & & & & & & & \\
\hline Time: 2 Minutes & & & & & & & & \\
\hline Demand: Low & 0.93 & 0.27 & 0.02 & 0.04 & 1.15 & 0.34 & 0.07 & 0.11 \\
\hline Demand: High & 0.93 & 0.27 & 0.02 & 0.03 & 1.16 & 0.34 & 0.12 & 0.23 \\
\hline Time: 4 Minutes & & & & & & & & \\
\hline Demand: Low & 0.93 & 0.30 & 0.02 & 0.04 & 1.19 & 0.45 & 0.12 & 0.24 \\
\hline Demand: High & 0.94 & 0.25 & 0.02 & 0.04 & 1.16 & 0.30 & 0.09 & 0.17 \\
\hline Time: 8 Minutes & & & & & & & & \\
\hline Demand: Low & 0.93 & 0.35 & 0.02 & 0.03 & 1.17 & 0.37 & 0.11 & 0.19 \\
\hline Demand: High & 0.97 & 0.29 & 0.02 & 0.03 & 1.22 & 0.38 & 0.10 & 0.18 \\
\hline Block 5 & & & & & & & & \\
\hline Time: 2 Minutes & & & & & & & & \\
\hline Demand: Low & 0.92 & 0.30 & 0.04 & 0.12 & 1.14 & 0.36 & 0.10 & 0.13 \\
\hline Demand: High & 0.93 & 0.29 & 0.03 & 0.08 & 1.16 & 0.39 & 0.13 & 0.24 \\
\hline Time: 4 Minutes & & & & & & & & \\
\hline Demand: Low & 0.91 & 0.28 & 0.03 & 0.05 & 1.17 & 0.37 & 0.13 & 0.23 \\
\hline Demand: High & 0.94 & 0.33 & 0.03 & 0.05 & 1.17 & 0.35 & 0.10 & 0.18 \\
\hline Time: 8 Minutes & & & & & & & & \\
\hline Demand: Low & 0.91 & 0.33 & 0.05 & 0.12 & 1.13 & 0.39 & 0.12 & 0.20 \\
\hline Demand: High & 0.95 & 0.26 & 0.03 & 0.11 & 1.20 & 0.38 & 0.12 & 0.22 \\
\hline
\end{tabular}




\begin{tabular}{|c|c|c|c|c|c|c|c|c|}
\hline \multirow[b]{3}{*}{ Block and Condition } & \multicolumn{4}{|c|}{ Congruent } & \multicolumn{4}{|c|}{ Incongruent } \\
\hline & \multicolumn{2}{|c|}{ Response Time } & \multicolumn{2}{|c|}{ Error Rate } & \multicolumn{2}{|c|}{ Response Time } & \multicolumn{2}{|c|}{ Error Rate } \\
\hline & $M$ & $S D$ & $M$ & $S D$ & $M$ & $S D$ & $M$ & $S D$ \\
\hline \multicolumn{9}{|l|}{ Block 1} \\
\hline \multicolumn{9}{|l|}{ Time: 2 Minutes } \\
\hline Demand: Low & 1.52 & 0.63 & 0.02 & 0.06 & 1.85 & 0.71 & 0.35 & 0.37 \\
\hline Demand: High & 1.51 & 0.64 & 0.02 & 0.06 & 1.82 & 0.70 & 0.35 & 0.38 \\
\hline \multicolumn{9}{|l|}{ Time: 4 Minutes } \\
\hline Demand: Low & 1.50 & 0.80 & 0.01 & 0.05 & 1.85 & 0.83 & 0.45 & 0.40 \\
\hline Demand: High & 1.48 & 0.69 & 0.01 & 0.05 & 1.85 & 0.77 & 0.41 & 0.40 \\
\hline \multicolumn{9}{|l|}{ Time: 8 Minutes } \\
\hline Demand: Low & 1.42 & 0.66 & 0.02 & 0.06 & 1.76 & 0.81 & 0.46 & 0.42 \\
\hline Demand: High & 1.51 & 0.67 & 0.02 & 0.08 & 1.88 & 0.85 & 0.40 & 0.42 \\
\hline \multicolumn{9}{|l|}{ Block 2} \\
\hline \multicolumn{9}{|l|}{ Time: 2 Minutes } \\
\hline Demand: Low & 1.39 & 0.56 & 0.01 & 0.03 & 1.75 & 0.66 & 0.26 & 0.35 \\
\hline Demand: High & 1.37 & 0.56 & 0.02 & 0.06 & 1.76 & 0.65 & 0.26 & 0.33 \\
\hline \multicolumn{9}{|l|}{ Time: 4 Minutes } \\
\hline Demand: Low & 1.37 & 0.54 & 0.02 & 0.10 & 1.68 & 0.59 & 0.30 & 0.34 \\
\hline Demand: High & 1.37 & 0.54 & 0.03 & 0.08 & 1.74 & 0.68 & 0.26 & 0.32 \\
\hline \multicolumn{9}{|l|}{ Time: 8 Minutes } \\
\hline Demand: Low & 1.33 & 0.54 & 0.02 & 0.06 & 1.66 & 0.60 & 0.36 & 0.37 \\
\hline Demand: High & 1.42 & 0.53 & 0.02 & 0.07 & 1.84 & 0.87 & 0.30 & 0.36 \\
\hline \multicolumn{9}{|l|}{ Block 3} \\
\hline \multicolumn{9}{|l|}{ Time: 2 Minutes } \\
\hline Demand: Low & 1.29 & 0.47 & 0.02 & 0.06 & 1.65 & 0.62 & 0.22 & 0.33 \\
\hline Demand: High & 1.25 & 0.46 & 0.01 & 0.04 & 1.63 & 0.57 & 0.23 & 0.31 \\
\hline \multicolumn{9}{|l|}{ Time: 4 Minutes } \\
\hline Demand: Low & 1.33 & 0.60 & 0.03 & 0.09 & 1.61 & 0.55 & 0.25 & 0.33 \\
\hline Demand: High & 1.29 & 0.45 & 0.01 & 0.04 & 1.65 & 0.62 & 0.24 & 0.32 \\
\hline Time: 8 Minutes & & & & & & & & \\
\hline Demand: Low & 1.21 & 0.42 & 0.02 & 0.06 & 1.54 & 0.55 & 0.31 & 0.36 \\
\hline Demand: High & 1.29 & 0.52 & 0.02 & 0.08 & 1.69 & 0.76 & 0.28 & 0.35 \\
\hline Block 4 & & & & & & & & \\
\hline Time: 2 Minutes & & & & & & & & \\
\hline Demand: Low & 1.20 & 0.40 & 0.03 & 0.08 & 1.51 & 0.55 & 0.22 & 0.31 \\
\hline Demand: High & 1.20 & 0.38 & 0.02 & 0.06 & 1.50 & 0.51 & 0.18 & 0.28 \\
\hline Time: 4 Minutes & & & & & & & & \\
\hline Demand: Low & 1.21 & 0.59 & 0.02 & 0.08 & 1.49 & 0.50 & 0.25 & 0.32 \\
\hline Demand: High & 1.20 & 0.44 & 0.02 & 0.07 & 1.52 & 0.49 & 0.22 & 0.32 \\
\hline Time: 8 Minutes & & & & & & & & \\
\hline Demand: Low & 1.22 & 0.48 & 0.03 & 0.07 & 1.52 & 0.52 & 0.30 & 0.35 \\
\hline Demand: High & 1.26 & 0.52 & 0.02 & 0.08 & 1.61 & 0.61 & 0.25 & 0.34 \\
\hline Block 5 & & & & & & & & \\
\hline Time: 2 Minutes & & & & & & & & \\
\hline Demand: Low & 1.13 & 0.36 & 0.04 & 0.10 & 1.42 & 0.49 & 0.21 & 0.31 \\
\hline Demand: High & 1.19 & 0.50 & 0.02 & 0.10 & 1.47 & 0.52 & 0.22 & 0.30 \\
\hline Time: 4 Minutes & & & & & & & & \\
\hline Demand: Low & 1.19 & 0.43 & 0.03 & 0.10 & 1.47 & 0.56 & 0.26 & 0.33 \\
\hline Demand: High & 1.20 & 0.44 & 0.02 & 0.07 & 1.47 & 0.50 & 0.22 & 0.33 \\
\hline Time: 8 Minutes & & & & & & & & \\
\hline Demand: Low & 1.14 & 0.41 & 0.04 & 0.15 & 1.41 & 0.58 & 0.31 & 0.36 \\
\hline Demand: High & 1.18 & 0.39 & 0.03 & 0.09 & 1.52 & 0.56 & 0.24 & 0.33 \\
\hline
\end{tabular}


Table S10

Results of ANOVAs for Performance Indicators in the Stroop Task

\begin{tabular}{|c|c|c|c|c|c|c|c|}
\hline \multirow[b]{2}{*}{ Effect } & \multirow[b]{2}{*}{$d f$} & \multicolumn{3}{|c|}{ Response Time } & \multicolumn{3}{|c|}{ Error Rate } \\
\hline & & $F$ & $\eta_{\mathrm{G}}^{2}$ & $p$ & $F$ & $\eta_{\mathrm{G}}^{2}$ & $p$ \\
\hline D & 1,650 & 0.53 & $<.001$ & .467 & 1.69 & $<.001$ & 0.193 \\
\hline $\mathrm{T}$ & 2,650 & 0.04 & $<.001$ & .963 & 3.58 & .002 & 0.029 \\
\hline $\mathrm{D} \times \mathrm{T}$ & 2,650 & 0.95 & .002 & .386 & 0.84 & $<.001$ & 0.433 \\
\hline I & 1,650 & 1376.42 & .112 & $<.001$ & 236.67 & .052 & $<.001$ \\
\hline$D \times 1$ & 1,650 & 0.55 & $<.001$ & .458 & 1.17 & $<.001$ & 0.281 \\
\hline $\mathrm{T} \times \mathrm{I}$ & 2,650 & 0.24 & $<.001$ & .784 & 2.26 & .001 & 0.106 \\
\hline$D \times T \times I$ & 2,650 & 0.30 & $<.001$ & .743 & 0.12 & $<.001$ & 0.884 \\
\hline $\mathrm{S}$ & 1,650 & 1939.92 & .081 & $<.001$ & 710.44 & .154 & $<.001$ \\
\hline$D \times S$ & 1,650 & 1.44 & $<.001$ & .230 & 1.02 & $<.001$ & 0.313 \\
\hline $\mathrm{T} \times \mathrm{S}$ & 2,650 & 1.03 & $<.001$ & .359 & 4.29 & .002 & 0.014 \\
\hline $\mathrm{D} \times \mathrm{T} \times \mathrm{S}$ & 2,650 & 1.76 & $<.001$ & .173 & 1.04 & $<.001$ & 0.354 \\
\hline B & $4,2600^{a}$ & 191.59 & .041 & $<.001$ & 23.69 & .003 & $<.001$ \\
\hline$D \times B$ & $4,2600^{a}$ & 0.20 & $<.001$ & .873 & 0.33 & $<.001$ & 0.797 \\
\hline$T \times B$ & $8,2600^{a}$ & 1.26 & $<.001$ & .278 & 1.28 & $<.001$ & 0.264 \\
\hline $\mathrm{D} \times \mathrm{T} \times \mathrm{B}$ & $8,2600^{a}$ & 0.65 & $<.001$ & .668 & 0.23 & $<.001$ & 0.963 \\
\hline$I \times S$ & 1,650 & 84.98 & .002 & $<.001$ & 236.62 & .050 & $<.001$ \\
\hline$D \times I \times S$ & 1,650 & 1.41 & $<.001$ & .235 & 0.82 & $<.001$ & 0.365 \\
\hline $\mathrm{T} \times \mathrm{I} \times \mathrm{S}$ & 2,650 & 1.11 & $<.001$ & .332 & 1.78 & $<.001$ & 0.170 \\
\hline$D \times T \times I \times S$ & 2,650 & 1.51 & $<.001$ & .222 & 0.19 & $<.001$ & 0.828 \\
\hline$I \times B$ & $4,2600^{b}$ & 34.88 & .003 & $<.001$ & 55.00 & .008 & $<.001$ \\
\hline$D \times I \times B$ & $4,2600^{b}$ & 0.89 & $<.001$ & .458 & 0.402 & $<.001$ & 0.774 \\
\hline $\mathrm{T} \times \mathrm{I} \times \mathrm{B}$ & $8,2600^{b}$ & 1.56 & $<.001$ & .142 & 0.80 & $<.001$ & 0.583 \\
\hline$D \times T \times I \times B$ & $8,2600^{b}$ & 0.58 & $<.001$ & .778 & 0.68 & $<.001$ & 0.681 \\
\hline$S \times B$ & $4,2600^{c}$ & 6.74 & $<.001$ & $<.001$ & 48.61 & .004 & $<.001$ \\
\hline$D \times S \times B$ & $4,2600^{c}$ & 0.81 & $<.001$ & .515 & 0.49 & $<.001$ & 0.697 \\
\hline $\mathrm{T} \times \mathrm{S} \times \mathrm{B}$ & $8,2600^{c}$ & 0.43 & $<.001$ & .901 & 1.51 & $<.001$ & 0.169 \\
\hline $\mathrm{D} \times \mathrm{T} \times \mathrm{S} \times \mathrm{B}$ & $8,2600^{c}$ & 0.22 & $<.001$ & .986 & 0.62 & $<.001$ & 0.719 \\
\hline$I \times S \times B$ & $4,2600^{d}$ & 2.05 & $<.001$ & .087 & 55.12 & .008 & $<.001$ \\
\hline$D \times 1 \times S \times B$ & $4,2600^{d}$ & 0.04 & $<.001$ & .997 & 1.03 & $<.001$ & 0.385 \\
\hline $\mathrm{T} \times 1 \times \mathrm{S} \times \mathrm{B}$ & $8,2600^{d}$ & 0.62 & $<.001$ & .757 & 1.48 & $<.001$ & 0.172 \\
\hline $\mathrm{D} \times \mathrm{T} \times \mathrm{I} \times \mathrm{S} \times \mathrm{B}$ & $8,2600^{d}$ & 0.28 & $<.001$ & .970 & 0.66 & $<.001$ & 0.699 \\
\hline
\end{tabular}

Note: $\mathrm{D}=$ Demand, $\mathrm{T}=$ Time, $\mathrm{I}=$ Instruction, $\mathrm{B}=\mathrm{Block}, \mathrm{S}=$ Stimulus. Significant effects are bold.

Degrees of freedom are Greenhouse-Geisser corrected $\left(\varepsilon_{\mathrm{GG}}\right)$ after a significant Mauchly test on

sphericity.

${ }^{a}$ Response Time: $\varepsilon_{\mathrm{GG}}=0.65$, Error Rate: $\varepsilon_{\mathrm{GG}}=0.72$

${ }^{\mathrm{b}}$ Response Time: $\varepsilon_{\mathrm{GG}}=0.88$, Error Rate: $\varepsilon_{\mathrm{GG}}=0.82$

' Response Time: $\varepsilon_{\mathrm{GG}}=0.97$, Error Rate: $\varepsilon_{\mathrm{GG}}=0.78$

${ }^{\mathrm{d}}$ Response Time: $\varepsilon_{\mathrm{GG}}=0.97$, Error Rate: $\varepsilon_{\mathrm{GG}}=0.84$ 


\section{Regression Analyses}

We analyzed state boredom after the transcription task and trait boredom as predictors of performance in the Stroop task. Because these predictors are continuous, we resorted to multilevel regression models implemented in the package Ime4 (Bates et al., 2015). For the analysis of errors, we used a generalized linear mixed effects model with a binomial link function to account for the discrete $0-1$ distribution of errors. For the analysis of response times, we used a linear mixed effects model with inverse transformation (i.e., $-1 / R T$ ) to account for the non-normal distribution of raw response times. In both analyses, we specified random intercepts on the participant level as well as for instruction, stimulus, and block. In addition to the analysis of these two behavioral performance measures, we employed diffusion modelling (Ratcliff \& Rouder, 1998; Voss et al., 2013) to estimate a set of latent parameters that characterize the information processing style that led to the observed performance (as suggested by Lin et al., 2020). These latent parameters were derived from the response time and error data (Wagenmakers et al., 2007) and reflect three main characteristics of the processing style: the speed of information processing (drift parameter), the degree to which accuracy is sacrificed for speed (boundary parameter), and the duration of preparing and implementing the decision (non-decisional parameter).

\section{Table S11}

Mixed-Effect Regression of Manifest and Latent Performance Indicators in the Stroop Task on State Boredom After the Transcription Task and Trait Boredom

\begin{tabular}{lccccc}
\hline & Response Time & Errors & Drift Rate & Boundary Separation & Non-Decision Time \\
\hline Intercept & $-0.915^{* * *}$ & $-3.422^{* * *}$ & $0.257^{* *}$ & $0.878^{* * *}$ & -0.185 \\
& $(0.176)$ & $(0.781)$ & $(0.085)$ & $(0.178)$ & $(0.276)$ \\
Boredom & $-0.010^{*}$ & 0.029 & -0.002 & $-0.014^{* *}$ & 0.013 \\
(State) & $(0.005)$ & $(0.023)$ & $(0.002)$ & $(0.005)$ & $(0.009)$ \\
Boredom & -0.012 & $0.070^{*}$ & -0.004 & $-0.017^{*}$ & 0.001 \\
(Trait) & $(0.007)$ & $(0.035)$ & $(0.003)$ & $(0.008)$ & $(0.013)$ \\
& & & & & -17362 \\
Log Likelihood & -116050 & -45221 & 5463 & -8691 & 12671 \\
\# Obs. & 217684 & 217684 & 12763 & 12671 & \\
Group Size & & & & & 642 \\
Participant & 642 & 642 & 642 & 642 & 5 \\
Block & 5 & 5 & 5 & 5 & 2 \\
Congruency & 2 & 2 & 2 & 2 & \\
Instruction & 2 & 2 & 2 & 2 & 0.135 \\
Variance & & & & & 0.001 \\
Participant & 0.055 & 1.160 & 0.006 & 0.052 & 0.144 \\
Block & 0.005 & 0.004 & 0.000 & 0.003 & 0.001 \\
Congruency & 0.025 & 1.441 & 0.014 & 0.038 & 0.842 \\
Instruction & 0.032 & 0.631 & 0.000 & 0.022 & \\
& 0.168 & & 0.023 & 0.210 & \\
\hline
\end{tabular}

Note. ${ }^{*} p<.05 .{ }^{* *} p<.01 .{ }^{* * *} p<.001$. 
We performed analogous analyses with state boredom during the Stroop task and trait boredom as predictors of performance, which yielded comparable results.

\section{Table S12}

Mixed-Effect Regression of Manifest and Latent Performance Indicators in the Stroop Task on State Boredom During the Stroop Task and Trait Boredom

\begin{tabular}{lccccc}
\hline & Response Time & Errors & Drift Rate & Boundary Separation & Non-Decision Time \\
\hline Intercept & $-0.906^{* * *}$ & $-3.322^{* * *}$ & $0.256^{* *}$ & $0.840^{* * *}$ & -0.153 \\
& $(0.175)$ & $(0.778)$ & $(0.085)$ & $(0.177)$ & $(0.274)$ \\
Boredom & $-0.007^{* * *}$ & 0.007 & $-0.003^{*}$ & $-0.007^{*}$ & 0.007 \\
(State) & $(0.001)$ & $(0.008)$ & $(0.001)$ & $(0.003)$ & $(0.006)$ \\
Boredom & -0.010 & $0.071^{*}$ & -0.003 & $-0.016^{*}$ & -0.000 \\
(Trait) & $(0.007)$ & $(0.035)$ & $(0.003)$ & $(0.008)$ & $(0.014)$ \\
& & & & & -17363 \\
Log Likelihood & -116027 & -45222 & 5465 & -8694 & 12671 \\
\# Obs. & 217684 & 217684 & 12763 & 12671 & 642 \\
Group Size & & & & & 5 \\
Participant & 642 & 642 & 642 & 642 & 2 \\
Block & 5 & 5 & 5 & 5 & 2 \\
Congruency & 2 & 2 & 2 & 2 & \\
Instruction & 2 & 2 & 2 & & 0.135 \\
Variance & & & & & 0.001 \\
Participant & 0.055 & 1.160 & 0.006 & 0.053 & 0.144 \\
Block & 0.004 & 0.004 & 0.000 & 0.002 & 0.001 \\
Congruency & 0.025 & 1.441 & 0.014 & 0.038 & 0.842 \\
Instruction & 0.032 & 0.631 & 0.000 & 0.022 & \\
& 0.168 & & 0.023 & 0.210 & \\
\hline
\end{tabular}

Note. ${ }^{*} p<.05 .{ }^{* *} p<.01 .{ }^{* * *} p<.001$. 


\section{References (Supplementary Material)}

Bates, D., Mächler, M., Bolker, B., \& Walker, S. (2015). Fitting linear mixed-effects models using Ime4. Journal of Statistical Software, 67(1). https://doi.org/10.18637/jss.v067.i01

Buhrmester, M., Kwang, T., \& Gosling, S. D. (2011). Amazon's Mechanical Turk: A new source of inexpensive, yet high-quality, data? Perspectives on Psychological Science, 6(1), 3-5. https://doi.org/10.1177/1745691610393980

Lin, H., Saunders, B., Friese, M., Evans, N. J., \& Inzlicht, M. (2020). Strong effort manipulations reduce response caution: A preregistered reinvention of the egodepletion paradigm. Psychological Science, 31(5), 531-547. https://doi.org/10.1177/0956797620904990

Litman, L., Robinson, J., \& Abberbock, T. (2017). Turkprime.Com: A versatile crowdsourcing data acquisition platform for the behavioral sciences. Behavior Research Methods, 49(2), 433-442. https://doi.org/10.3758/s13428-016-0727-z

Ratcliff, R., \& Rouder, J. N. (1998). Modeling response times for two-choice decisions. Psychological Science, 9(5), 347-356. https://doi.org/10.1111/1467-9280.00067

Voss, A., Nagler, M., \& Lerche, V. (2013). Diffusion models in experimental psychology: A practical introduction. Experimental Psychology, 60(6), 385-402.

https://doi.org/10.1027/1618-3169/a000218

Wagenmakers, E.-J., van der Maas, H. L. J., \& Grasman, R. P. P. P. (2007). An EZ-diffusion model for response time and accuracy. Psychonomic Bulletin \& Review, 14(1), 3-22. https://doi.org/10.3758/bf03194023 